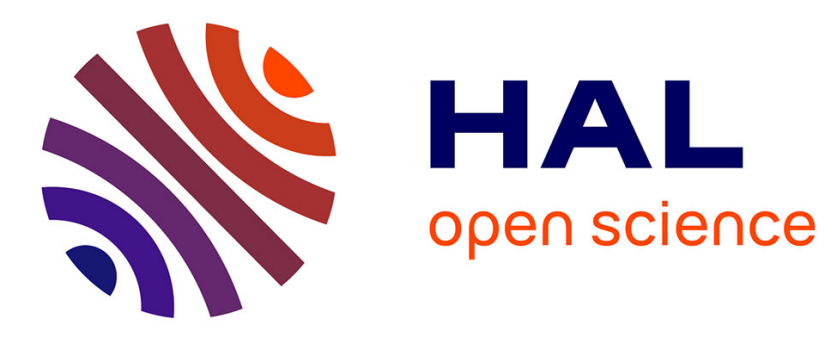

\title{
Extraction of microstructural parameters from sculptured thin films nanoindentation
}

Yves Gaillard, Emilio Jimenez-Piqué, Manuel Oliva-Ramirez, Victor Joaquin Rico, Agustin R Gonzalez-Elipe

\section{- To cite this version:}

Yves Gaillard, Emilio Jimenez-Piqué, Manuel Oliva-Ramirez, Victor Joaquin Rico, Agustin R Gonzalez-Elipe. Extraction of microstructural parameters from sculptured thin films nanoindentation. Surface and Coatings Technology, 2021, 425, pp.127696 (13). hal-03549374

\section{HAL Id: hal-03549374 \\ https://hal.science/hal-03549374}

Submitted on 31 Jan 2022

HAL is a multi-disciplinary open access archive for the deposit and dissemination of scientific research documents, whether they are published or not. The documents may come from teaching and research institutions in France or abroad, or from public or private research centers.
L'archive ouverte pluridisciplinaire HAL, est destinée au dépôt et à la diffusion de documents scientifiques de niveau recherche, publiés ou non, émanant des établissements d'enseignement et de recherche français ou étrangers, des laboratoires publics ou privés. 
Extraction of microstructural parameters from sculptured thin film's nanoindentation

\author{
Y. Gaillard ${ }^{1}$, E. Jimenez-Piqué ${ }^{2,3}$, M. Oliva-Ramirez ${ }^{4}$, V. J. Rico ${ }^{4}$, A. R Gonzalez-Elipe ${ }^{4}$. \\ 1) Department of Applied Mechanics, FEMTO-ST institute, 24 rue de l'épitaphe, 25000 Besançon. \\ 2) Department of Materials Science and Engineering, EEBE, Universitat Politécnica de Catalunya, \\ C/Eduard Maristany, 10-14, 08019 Barcelona, Spain.
}

3) Barcelona Research Center in Multiscale Science and Engineering, Universitat Politécnica de Catalunya, C/Eduard Maristany, 10-14, 08019 Barcelona, Spain.

4) Laboratory of Nanotechnology on Surfaces, Institute of Materials Science of Seville (CSIC-Univ. Sevilla), Calle Américo Vespucio 49, 41092, Sevilla, Spain

\begin{abstract}
:
This work deals with the indentation analysis of nanocolumnar thin films and the difficulties encountered to deduce relevant mechanical parameters by this methodology. $\mathrm{SiO}_{2}$ thin films prepared by physical vapour oblique angle deposition with different nanocolumnar microstructures have been subjected to indentation analysis. Despite the fact that the films had been made of the same material, deposited on the same substrate and had similar thickness, their indentation responses were different and depended on their particular microstructure. It has been also realised that the measured hardness and elastic modulus variation with the indentation depth were length scale dependent and that there is not a unique analytical thin-film nanoindentation model to extract the mechanical properties from the experimental nanoindentation curves. To overcome these limitations a numerical finite element model (FEM) of the nanocolumnar coatings has been built to figure out the contributions of the different physical phenomena intervening in the indentation process. This FEM simulation relies on a description of the elasto-plastic microstructural units of the coatings and the contact friction interactions between them. Based on this simulation a parametrical representation, incorporating two length scales and the contributions of densification and/or the buckling of nanocolumnar units, has been developed to account for the evolution of the apparent elastic modulus deduced from numerical indentation tests. A Hall-Petch modification of this description considering two length scales instead of the common approximation considering a single length scale has rendered the best agreement with the elastic values determined experimentally. Although, at the present stage, the particular microstructure of the films can not be deduced from the evolution of their elastic moduli with the indentation depth, the obtained results and their interpretation constitute a first though essential step for the elaboration of an inverse analysis methodology capable of correlating microstructure and elastic response of nanocolumnar coatings.
\end{abstract}

\title{
1. Introduction:
}

Oxide thin films prepared by oblique angle deposition (OAD), either evaporation [[1], [2], [3], [4]] or magnetron sputtering [[5], [6], [7], [8]], are attracting a considerable interest as host and templates for the fabrication of other materials and nanostructures. Using this approach, splats, nanocolumns, helix and other complex sculptural shapes can be tailored during deposition [[9], [10]]. Nanocolumnar single or stacked films can be also tailored to bestow a particular optical or functional property to the deposited layers [[11], [12], [13]]. In fact, thin films fabricated by physical vapour 
oblique angle deposition (PVOAD) may present different microstructures that provide a strict control over optical properties such as refraction index [[14]] or optical anisotropy and birefringence [[15]]. Such a fine control provides a straightforward way to develop optically active photonic structures [[16]] or helicoidally anisotropic media acting, for example, as narrow band-pass optical filters [[1]], selective circularly or linearly polarised light transmitters [[16], [17]] [[18]]. In these optical systems, the number of layers, the deposition configuration and the zenithal evaporation angle give rise to a large variety of nanocolumns with well-defined inclinations, diameters and shapes. Alternation between compact and porous layers can also be worked out.

From a mechanical point of view, these different configurations may incorporate various internal length scales modifying the intrinsic mechanical behaviour of the coatings material. Buckling, densification or shear banding are phenomena classically observed during indentation of columnar coatings [[19], [20], [21]] conferring specific mechanical properties that differ from those of the constituent material handled in bulk form [[22]]. The shape ratio of the column appears here as a fundamental parameter at the origin of, at least, one internal length scale dependence [[23]]. This feature manifests itself during indentation, due to a strong dependence existing between measured mechanical properties and indentation depth. The influence of specific length scales combined with the thin film structuration makes particularly difficult the mechanical characterisation of this type of coatings [[24], [25], [26]]. Deducing such length scale parameters is not trivial and this paper proposes a new systematic procedure to advance in the mechanical characterization of this type of nanocolumnar coatings.

Numerical simulation appears as an opportunity to better apprehend and understand the behaviour of such kind of coatings under indentation. However, this is not so trivial due to their columnar structure. Watanabe et al. [[21]], Crowell et al. [27]] choose to assimilate the intercolumnar region as foams, which is very useful for numerical integration but does not allow to take into account the effect of friction between columns, particularly on the phase shift response. In this paper, a full description of the columnar coating by a 2D finite element model has been preferred. This strategy has been also embraced by Zisis and Fleck [[28]], Chen et al. [[29]] but also Wang et al. [[30]]. However, this description is heavy, implying a great number of contact finite element and so a very slow numerical convergence that impedes its systematic use in a finite element model updating (FEMU) process due to very long calculation times. To overcome this restriction and to properly characterize the mechanical behaviour of nanocolumnar thin films with particular and distinct microstructures, a parametrical method has been developed here combining the description of the indentation process of the thin film [[31]], based on the FEM model of the columnar coatings, and a size dependent approximation.

The paper is organised as follows: first, we describe the experimental set-up and raw indentation results obtained on oblique angle deposition coatings samples having different structure. Second, we describe the finite element model simulation to analyse the thin film behaviour under indentation. The approach used for this purpose is empirical and consists in fitting mathematically the indentation response of a nanocolumnar coating, followed by the analysis of the numerical results given by the FEM model. Finally, based on the FEM approach, we discuss how to extract microstructural parameters for each type of nanocolumnar coating.

\section{Experimental procedure:}

\section{i. Fabrication of nanostructured multilayers:}


Uniform, generally highly porous, multilayer structures formed by the stacking of various $\mathrm{SiO}_{2}$ layers have been prepared by oblique angle deposition (OAD) according to the standard procedure utilized for the deposition of single-layer films [[32]]. Basically, the procedure consisted of the electron beam evaporation of $\mathrm{SiO}_{2}$ pellets under a residual pressure of oxygen of $4 \times 10^{-5} \mathrm{mbar}$ to ensure the total oxidation of the deposited $\mathrm{SiO}_{2}$ thin films. Soda lime glass and silicon substrates were placed at a distance of $50 \mathrm{~cm}$ from the evaporation source. The investigated porous and compact layers were ebeam-evaporated on soda-lime plates of $1.2 \times 2.5 \mathrm{~cm}^{2}$ at zenithal angles $(\alpha)$ of $0 \circ, 700$ and $80 \circ$. Depending on the arrangement of nanocolumns and compact segments, six different types of multilayers have been prepared depicting the following microstructures: compact $\mathrm{C}$ (i), vertical $\mathrm{V}$ (ii), slanted S (iii), zigzag ZZ (iv), chiral CHL (v), or a sequential mixture of slanted and compact CSC (vi) microstructures finishing in a compact layer. Compact, vertical and slanted layers were homogenous in depth, while zigzag, chiral and CSC layers had a multilayer structure consisting of 8 (zigzag) or 5 (chiral and CSC) individual segments with an approximate thickness of 200 and $300-400 \mathrm{~nm}$, respectively. The different nanocolumnar morphologies were obtained by keeping fix the zenithal angle of deposition for the slanted microstructure, while azimuthally turning the substrate from one layer to the next, either by $180^{\circ}$ in the zigzag or 90 in the chiral layers, and continuously rotating it at $40 \mathrm{rpm}$ for the vertical coatings, also at a zenithal angle of 70 . Total thickness varied from approximately 1300 to $2000 \mathrm{~nm}$ depending on the layer.

\section{ii. Microstructural characterization by SEM and AFM:}

Surface morphology of the films was determined by scanning electron microscopy (SEM) for thin films deposited on silicon wafers, which were diced for cross section imaging. This analysis was carried out in a Hitachi $\mathbf{S} 4800$ field emission microscope. Atomic force microscopy (AFM) measurements have been performed on a Park XE-150 microscope in order to characterise the column size at the top surface of the samples. After the binarization of the AFM images, average column sizes were determined using the WSxM software [[33]].

\section{iii. Instrumented indentation:}

Nanoindentation experiments have been performed using an Anton Paar ultra nanoindenter. $\underline{A}$ Berkovich tip, having a $72 \mathrm{~nm}$ radius of curvature (calculated from the stiffness versus contact depth relation and considering a $65.3^{\circ}$ face angle), has been used. In order to study the evolution of the mechanical properties with the indentation depth, $\underline{h}$, sinusoidal nanoindentations have been performed at a constant $\frac{\dot{h}}{h}$ value of $0.05 \mathrm{~s}^{-1}$. A sinusoidal contribution with a frequency of $5 \mathrm{~Hz}$ has been superimposed to the signal in order to measure the stiffness $S$, the force $F_{m}$ and the displacement throughout the loading part of the indentation process (continuous stiffness measurement). Shape area function has been calibrated through the indentation of a fused silica plate. Apparent indentation moduli $E_{a p p}^{*}$ and hardness $\mathrm{H}$ of the different multilayers have been determined using the procedure proposed by Oliver and Pharr [[34]].

\section{Finite Element Modelling Simulation analysis:}

A finite element model has been built in Ansys [Ansys V17.2]. Four noded quadrilateral elements have been employed to mesh a 2D finite element model. The geometry includes an undeformable triangular indenter, with a curvature radius of $100 \mathrm{~nm}$, and two hundred $1 \mathrm{~nm}$ spaced nanocolumns of $10 \mathrm{~nm}$ width and $500 \mathrm{~nm}$ length (Figure 1). These dimensions have been chosen to mimic the actual dimensions of nanocolumns in the OAD thin films, although the actual distribution of dimensions in 
the films has a large scatter of values around these average values. Contact elements are not only introduced between all adjacent nanocolumns but also between the nanocolumns and the indenter. For this purpose, two friction coefficients are used, the first one associated to the column-column contact and the second one associated to the indenter-columns contact. A Coulomb friction law is used for both contacts. The degrees of freedom (DOF) of the nodes composing the indenter were coupled. Meanwhile, the DOF of the nodes localised at the columns basis were also coupled and locked. For these simulations, the indenter penetrates the films and the resulting reaction force was obtained from the coupled set of nodes localised at the basis of the columns and the indenter. These two reaction forces presented the same value and opposite signs. The model includes 68000 elements and a total time of 227000 seconds CPU was required for the calculations. The mesh was refined near the contact.

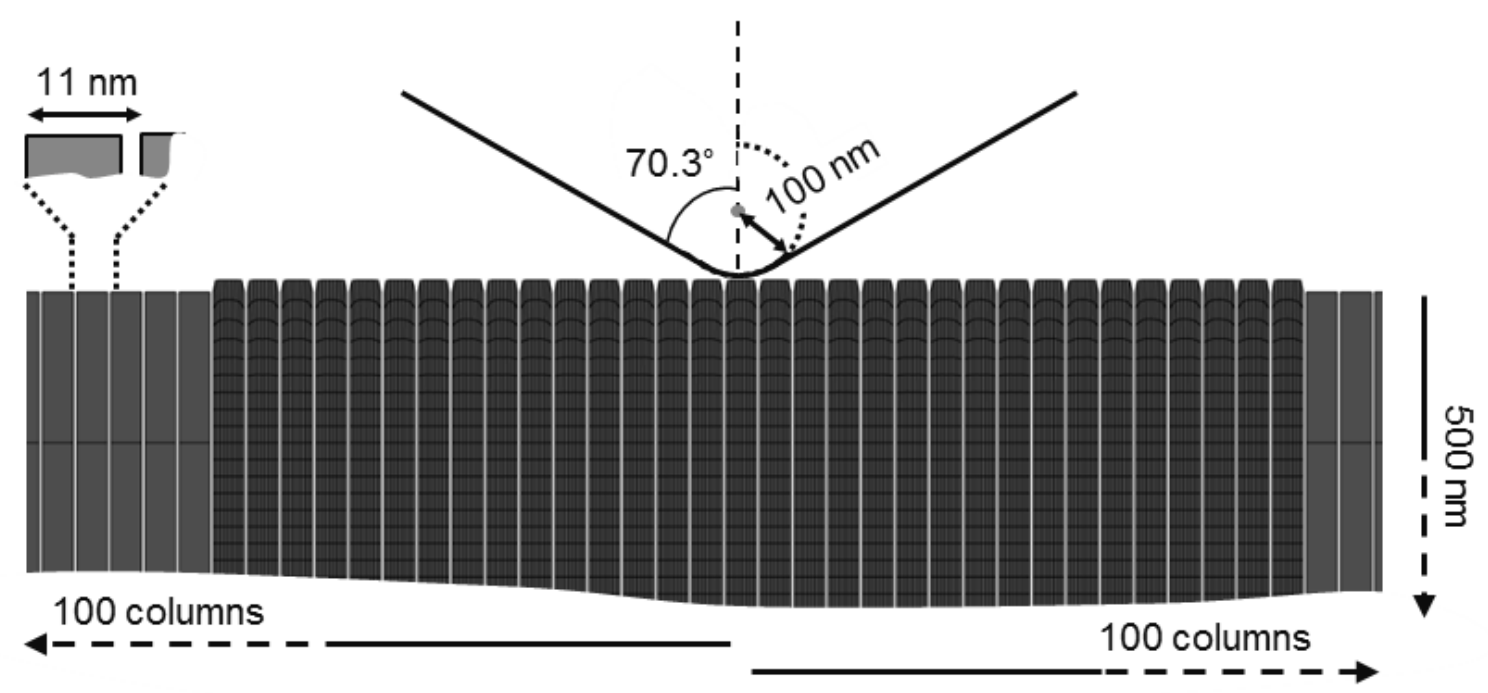

Figure 1: Scheme of the finite element model of the nanocolumnar structure.

The nanocolumns material is assumed to be time independent (not viscous), isotropic and elastoplastic. A bilinear law has been chosen arbitrary to describe its behaviour and four specific parameters were required for a straightforward description: an elastic modulus, a Poisson's ratio, a yield stress and a linear isotropic hardening modulus. These parameters were respectively set at 200, $0.3,0.2$ and $2 \mathrm{GPa}$.

\section{Results:}

\section{i. Microstructure of thin films:}

To determine the nanostructural factors responsible for the mechanical response of PV-OAD microstructures, six types of $\mathrm{SiO}_{2}$ multilayers have been prepared and characterized. They depict different nano-columnar arrangements that have been named as: (i) compact, deposited at alpha=0응 (ii) vertical (V), deposited by PVOAD while continuously rotating the substrate around its azimuth; (iii) slanted (S), prepared at constant azimuthal orientation of the substrate during deposition of the 
whole layer; (iv) zigzag (ZZ) and (v) chiral (CHL), formed by successive nanocolumnar segments with different orientations obtained by turning the substrate, respectively, by 180 and $90^{\circ}$ for each segment to the next in the stack; and (vi) a sequential mixture of slanted and compact microstructures (CSC) finishing in a compact one. Figure 2 displays a series of cross sections micrographs taken for these $\mathrm{SiO}_{2}$ coatings deposited on a silicon wafer at zenithal angles of 00 and $80 \circ$. In the notation used, the value of the zenithal angle appears after the film acronym (e.g., slanted S80, zigzag ZZ80 and CSC 80 ). Figure 3 presents typical atomic force microscopy measurements obtained for samples CSC70 (a), ZZ70 (b), Vertical (c), CHL70 (d) and S70 (e). AFM was used to calculate the average column size at the top surface of the sample. The determined average size of the nanostructure features at the surface was, respectively, $100 \pm 31 \mathrm{~nm}, 128 \pm 58 \mathrm{~nm}, 123 \pm 48 \mathrm{~nm}$, $90 \pm 38 \mathrm{~nm}$ and $83 \pm 28 \mathrm{~nm}$.

(a)

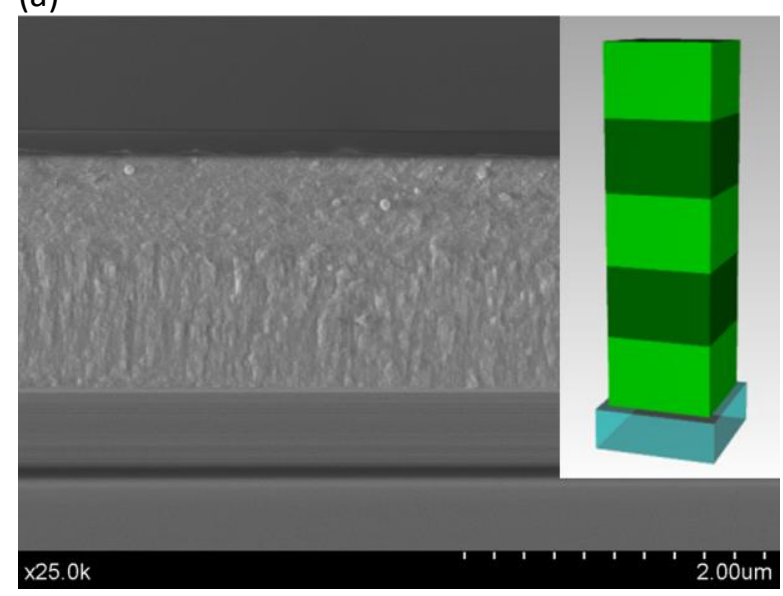

(c)

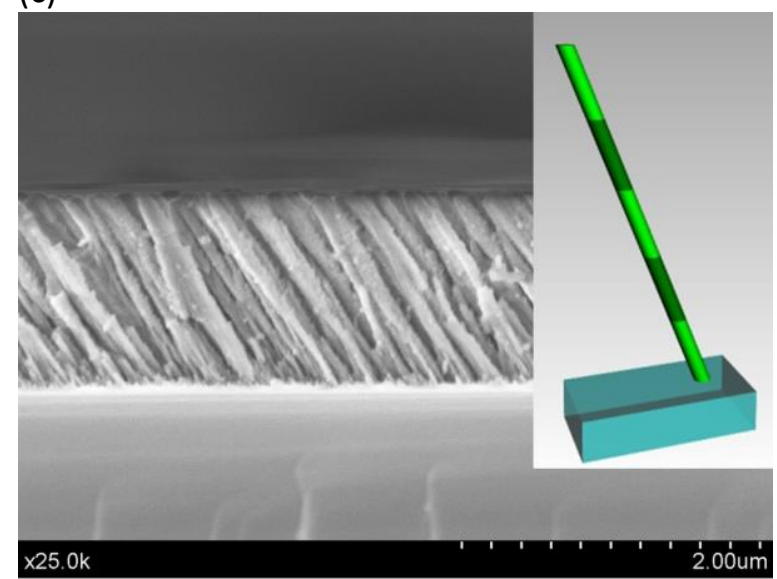

(b)

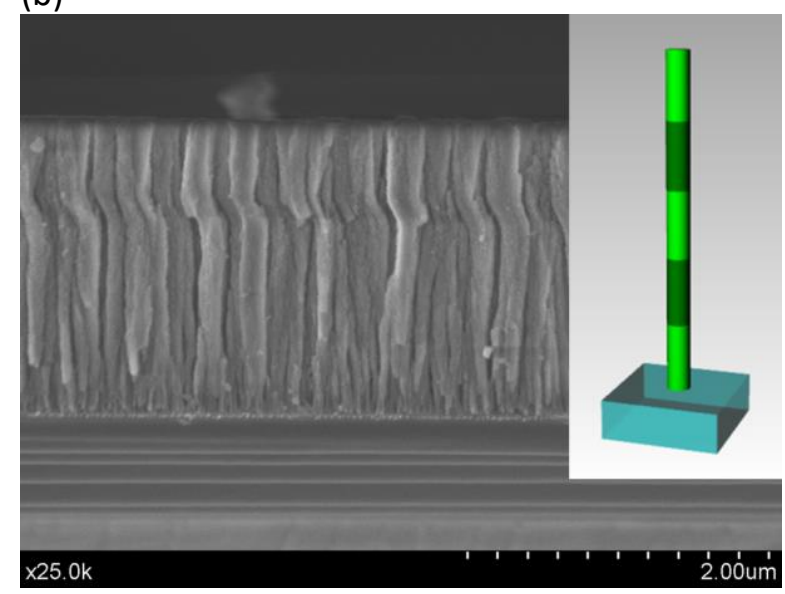

(d)

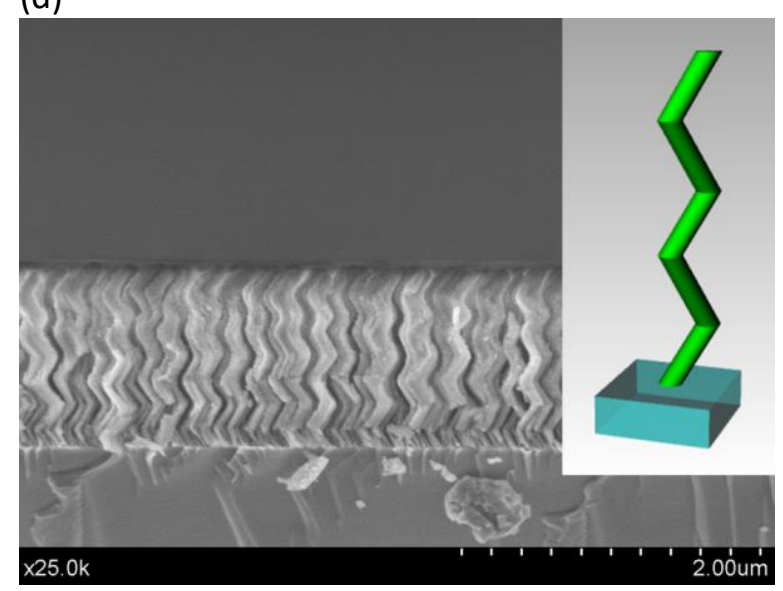

(e) 

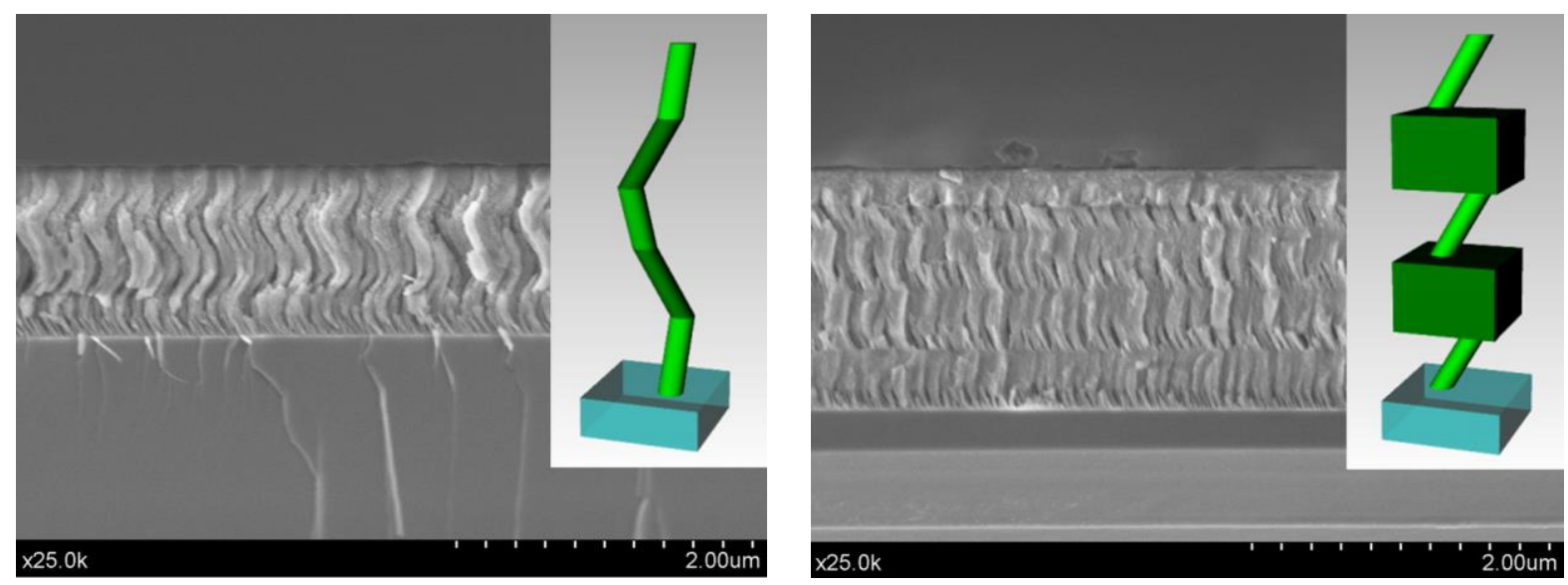

Figure 2: SEM cross section observation of the different nanocolumnar multilayers: compact $\mathrm{C}(\mathrm{a})$, vertical V (b), slanted S80 (c), zigzag ZZ80 (d), chiral CH80(e) and CSC80 (f). The schemes represent the orientation and stacking of nanocolumnar and compact film segments in each case.
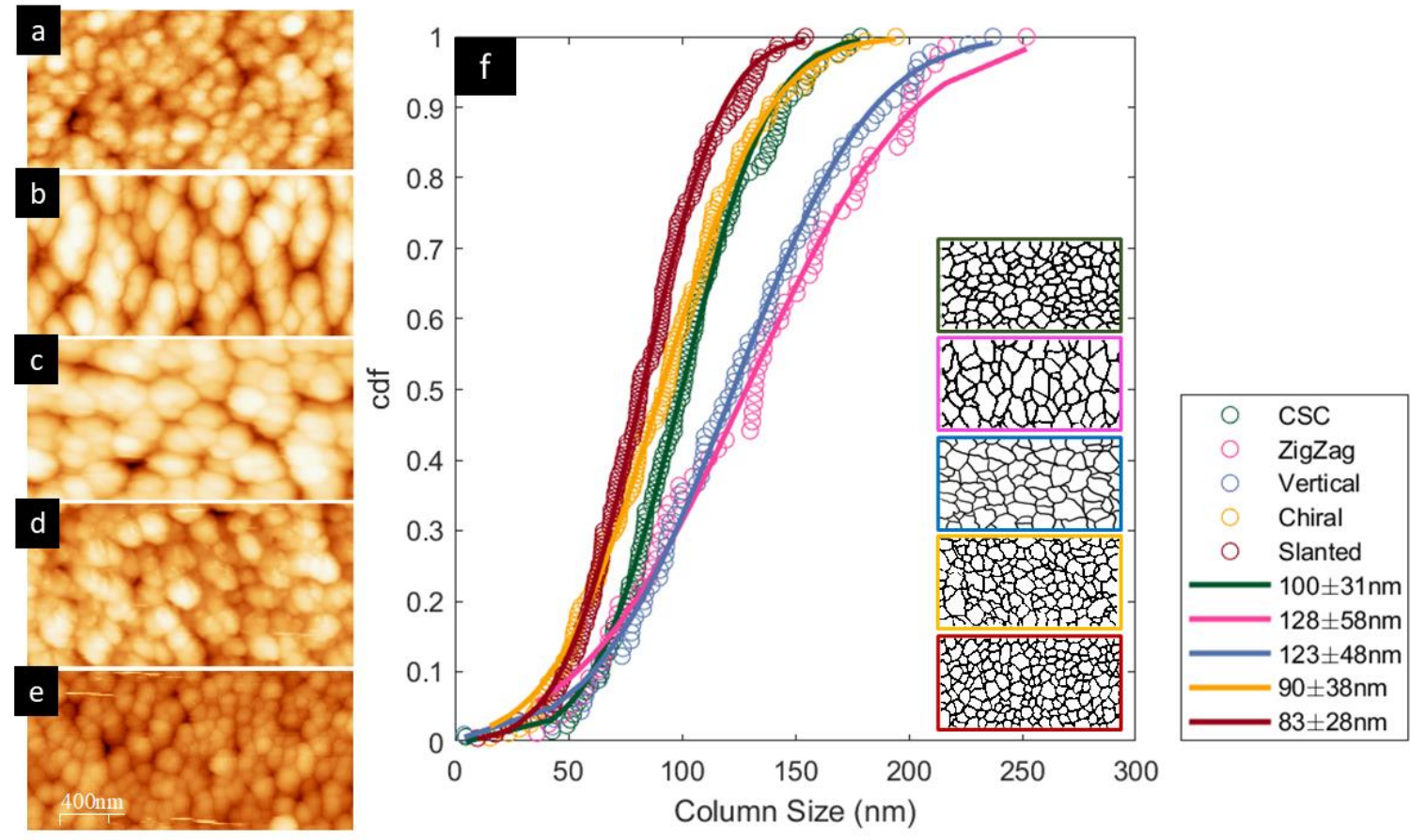

Figure 3: Atomic force microscopy (AFM) measurements obtained on the top surface of CSC70 (a) ZZ70 (b), Vertical (c), CHL70 (d) and $\mathrm{S70}$ (e) samples deposited on $\mathrm{SiO}_{2}$ substrates. (f) experimental and modelled cumulative density function (cdf) derived from the AFM image of the five samples.

\section{ii. Nanoindentation experiments:}

An example of the typical load displacement response, obtained on the vertical sample, is reported in figure 4. Indentation curves exhibit strong force drops that can be observed mainly during the first stages of deformation, i.e. for depth values smaller than $150 \mathrm{~nm}$. Continuous stiffness measurements depicted a significant phase shift between force and displacement. A non-zero phase shift reveals the 
occurrence of dissipation effects, which could be attributed to a viscous behaviour of the material or to friction phenomena associated with the particular structure of the coating. With respect to $\mathrm{SiO}_{2}$ in bulk form [[35]], such kind of behaviours are unexpected. In fact, plastic deformation of $\mathrm{SiO}_{2}$ is known to occur through local rearrangements, i.e., in the so-called shear twinned zone [[36], [37]], which evolves in a self-similar manner as the indenter penetrates the material. This behaviour leads to very smooth force displacement curves, but also to constant hardness and indentation elastic modulus within the range of penetration depth of the indenter, at least until material fracture occurs. These observations suggest that the nanocolumnar microstructure is the main cause of the displacement burst and phase shift reported in Figure 4.

(a)

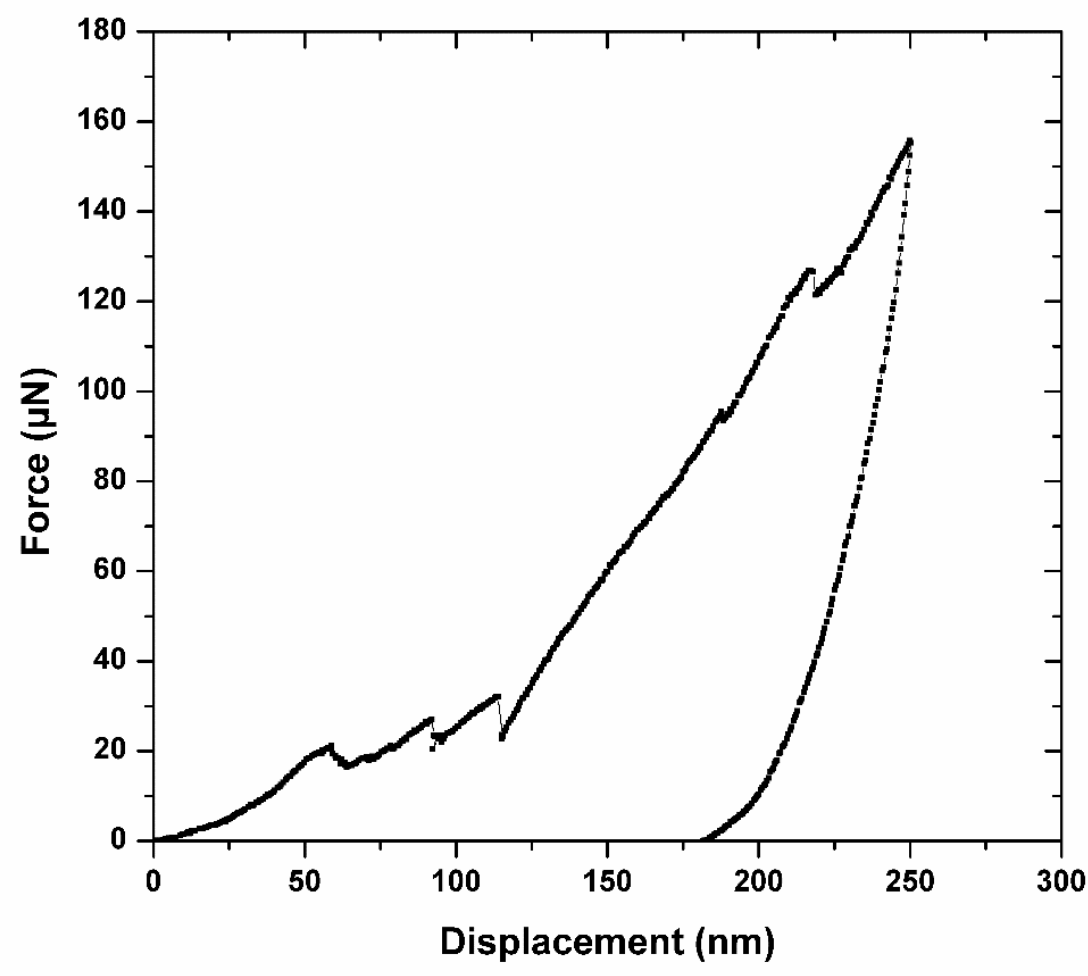

(b) 


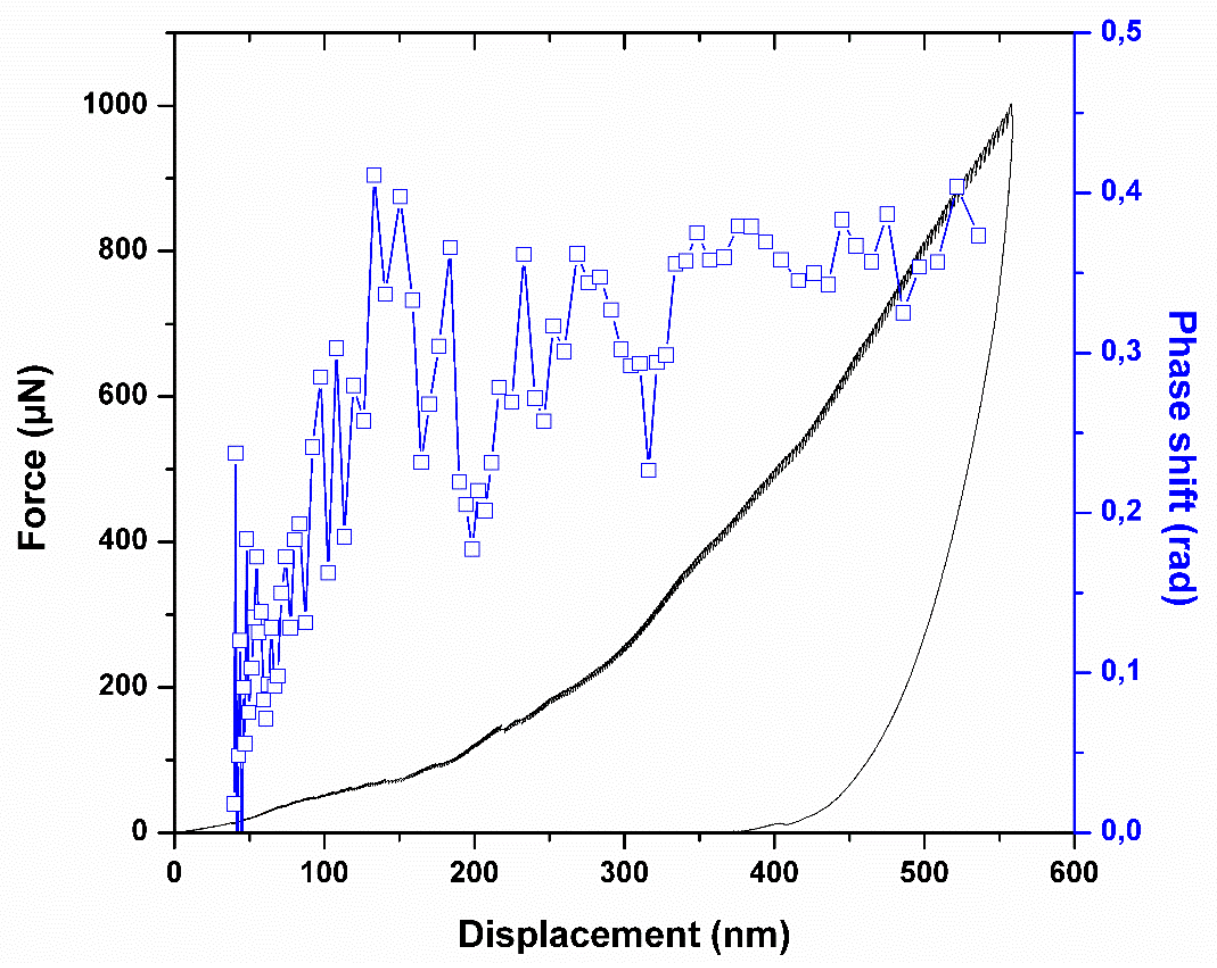

Figure 4: indentation curve recorded for the vertical sample V70: (a) load-displacement curve obtained during a monotonic indentation driven in displacement, and (b) evolution of force and phase shift as a function of indentation depth during an indentation performed in continuous stiffness measurement.

Figures 5 and 6 present the evolution of the hardness and apparent indentation elastic moduli extracted from the analysis of indentation curves by the Oliver and Pharr method [[34]]. They are presented in a logarithmic scale in order to show the results for all coatings in the same plot. Despite their similar chemical composition, coating's hardness and modulus were always lower than the equivalent magnitudes values of the substrate. It is also clear that both hardness and modulus exhibit strong variations with indentation depth. Moreover, the variation profiles were much dependent on the actual microstructure of the coatings, so that modulus and hardness can either increase monotonously (for the zigzag structure, for example) or decrease during the first stage of deformation to then increase with indentation depth (for the slanted layers, for example). 


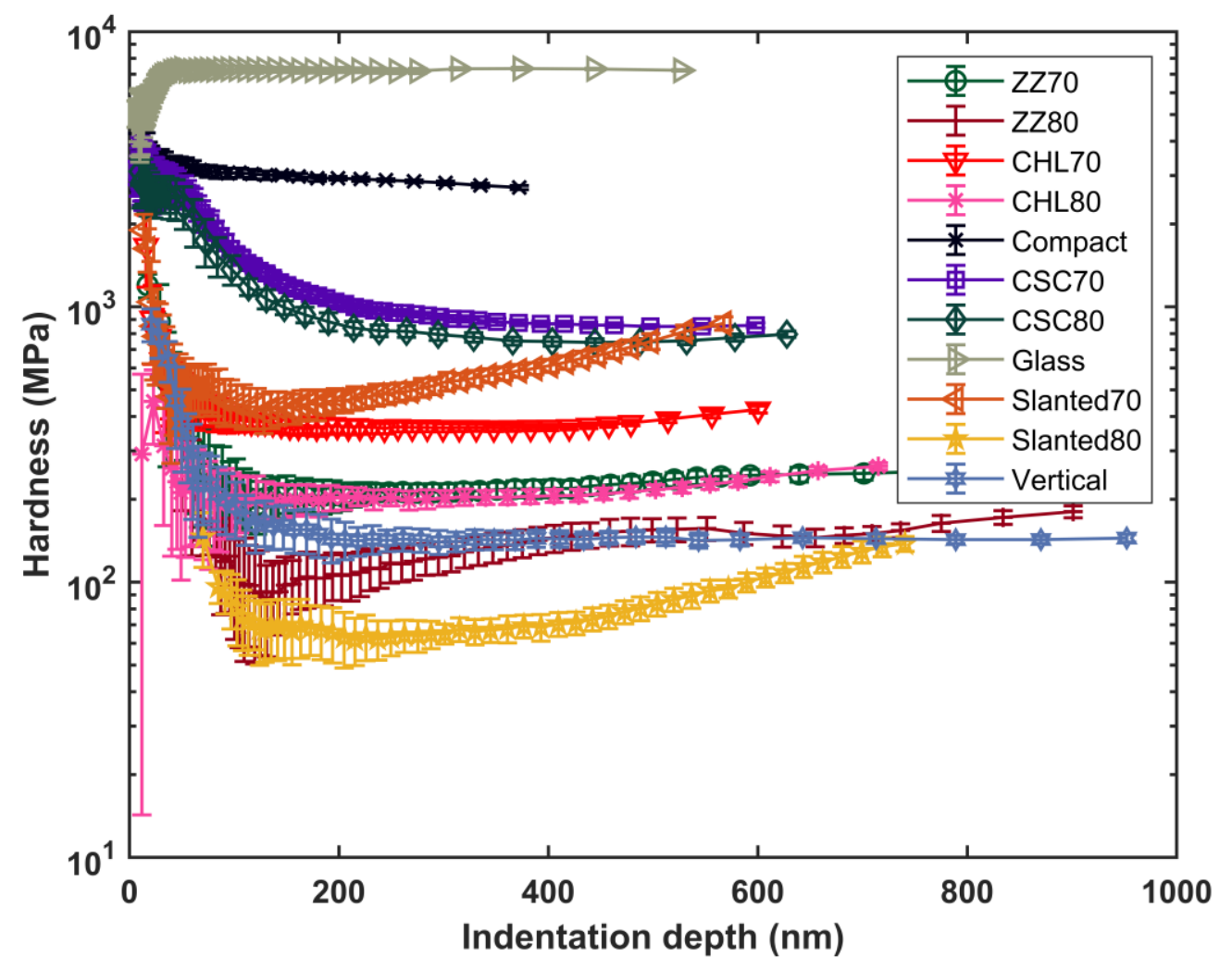

Figure 5: Evolution of the hardness (MPa) of the indicated multilayers with the indentation depth $(\mathrm{nm})$ 


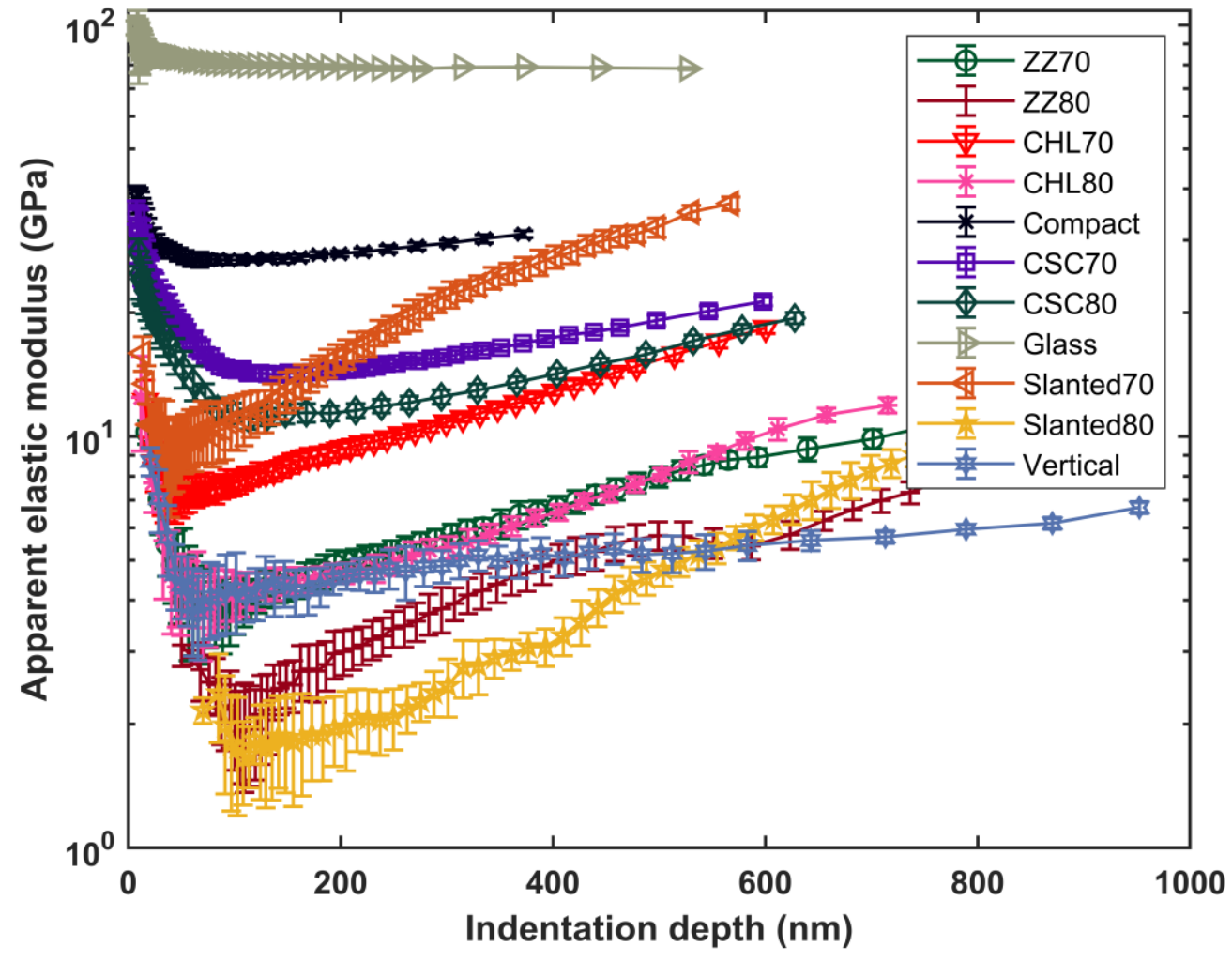

Figure 6: Evolution of the apparent elastic modulus $E_{a p p}^{*}(\mathrm{GPa})$ of the indicated multilayers with the indentation depth $(\mathrm{nm})$

Focusing on the behaviour of the compact and the CSC layers, it is noteworthy that, extrapolating their values to a zero-depth indentation, magnitudes of hardness and elastic modulus tend to the same value at very low indentation depths. On the other hand, since plastic strain field is less extended than the elastic strain field, a plateau was obtained for compact and CSC layers, both exhibiting a similar evolution for the shape of the hardness curve. This assessment suggests that the identification of the particular properties of the material composing the columns would be feasible using these three experimental responses (compact, CSC70 and CSC80), provided that the particular structure of the layer is explicitly taken into account for the analysis.

Figure 6 shows that both stiffening and softening effects are required to explain the evolution of the indentation modulus with indentation depth. This evidence also results from this analysis of layers with tilted columns (slanted, zigzag, and chiral), also suggesting that these layers are more prone to lose their structural integrity during the first step of indentation. In fact, to probe the nanocolumns material without any flexion of the column would require a very high resolution for the measurement of the modulus during the first ten nanometres of indentation. However, these microstructures tend also to recover from this loss of integrity. An elastic densification is probably the cause of this recovery.

\section{iii. Finite Element Simulation analysis:}

Figure 7 summarises the results obtained by finite element simulation analysis of the indentation process. Figure 7a shows the force-displacement curve obtained for an indentation simulation for a 
vertical nanostructure up to a penetration depth of $100 \mathrm{~nm}$. There, in the (P-h) curve, one can observe numerous discontinuities and force drops. The evolution of hardness, also shown in figure $7 \mathrm{a}$, has been obtained dividing the force by the contact area between indenter and vertical nanostructure. Figure $7 \mathrm{~b}$ shows the structure after deformation. Densification, buckling and shear bands are clearly observed in this snapshot. Figure 7c presents the simulation of an indentation process performed up to $25 \mathrm{~nm}$ of penetration depth. In this case the indentation depth is driven dynamically, performing 100 loading-unloading cycles with an amplitude of $2 \mathrm{~nm}$ during the test. In relation with the Continuous Stiffness Measurement (CSM) test performed experimentally, this simulated experiment allows us to determine the evolution of stiffness and phase shift with the indentation depth. The calculated depth evolution of the phase shift is also shown in figure 7c. Assuming that the elastic modulus of the indented layer is proportional to the stiffness divided by the square root of the contact area [[38]], [39]], it is possible to plot the evolution of the apparent elastic modulus with the indentation depth, as shown in Figure $7 \mathrm{~d}$. This representation shows that the modulus tends initially to decrease with the indentation depth due to the buckling of the indented nanocolumns. Then, from an indentation depth of about $9 \mathrm{~nm}$, the modulus increases with the penetration of the indenter, a feature that we link with that nanocolumns get in contact between them. These finite elements simulated results indicate that the evolution of elastic modulus with depth can be described as a competition between densification and buckling of nanocolumns.

(a)

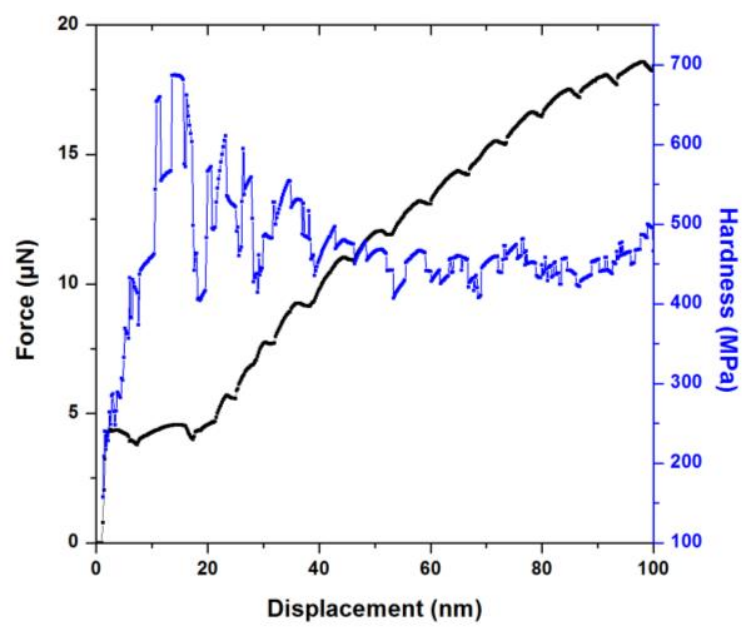

(c) (b)

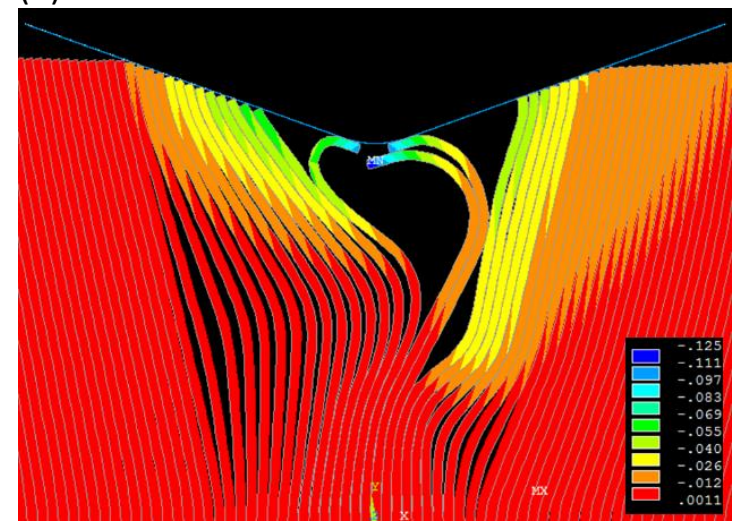

(d) 

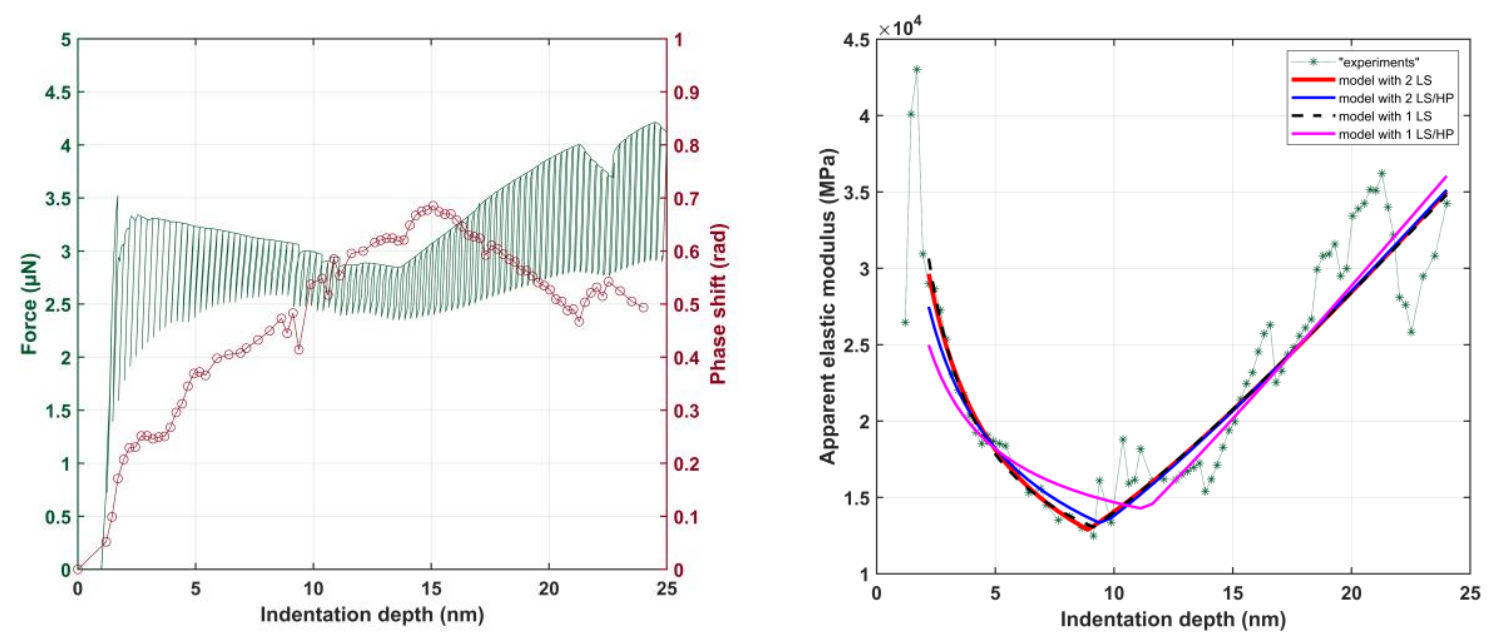

Figure 7: Numerical results obtained by FEM simulation: (a) Evolution of the load and the hardness with the indentation depth during a monotonic indentation performed until 100nm, (b) snapshot of the resulting deformed structure, the coloured scaled characterises the vertical displacement of each node, (c) Evolution of force and phase shift during a sinusoidal indentation performed up to a penetration of $25 \mathrm{~nm}$ and (d) evolution with the indentation depth of the FEM calculated elastic modulus.

\section{iv. Thin film mechanical properties and parametrical evaluation of the mechanical response:}

In the literature on the subject, there are a variety of parametric thin film models aiming at extracting the value of the elastic modulus of a film from its experimental indentation response. Since most of these models yield similar results we have used the Bec et al. approach [[31], [40]] because of its simplicity. By this procedure, the apparent elastic modulus of a film, $E_{a p p}^{*}$, is obtained using the expression:

$$
\frac{1}{2 a_{c} E_{a p p}^{*}}=\frac{1}{1+\frac{2 t_{e f f}}{\pi a_{C}}}\left(\frac{t_{e f f}}{\pi a_{c}^{2} E_{F}^{*}}+\frac{1}{2 a_{c} E_{S}^{*}}\right)
$$

with $t_{e f f}=t-\frac{h_{c}}{3}$, where $h_{c}$ is the contact depth, $a_{c}$ the contact radius (deduced from the contact area) and $t$ the thickness of the film. $E_{F}^{*}$ and $E_{S}^{*}$ are the equivalent elastic indentation modulus of the film and the substrate, respectively., Thus, knowing the experimental values of $S, F_{m}$ and $h$, the data available for $\mathrm{t}$ and $E_{S}^{*}$ and assuming a starting value for $E_{F}^{*}$, it is possible to calculate a value for $E_{a p p}^{*}$.

Most of the available approaches, including that by Bec et al. (2010), apply to dense isotropic coatings, a type of microstructure that does not correspond to the nanocolumnar configuration of the coatings studied here. This means that the proposed parametric formulas have to be modified to properly account for the actual film mechanical properties.

For the nanocolumnar films, assuming that densification would induce a linear increase of the indentation modulus with depth, the following relation can be used to describe the evolution of the indentation modulus with the indentation depth $\left(E_{F}=E_{F}(h)\right)$ :

$$
E_{F}^{*}(h)=E_{\text {LIN }}\left(h-l_{1}\right)
$$

Where $E_{L I N}$ is the elastic stiffening coefficient, and $I_{1}$ is a characteristic length that we propose to fit parametrically to the FEM simulation results. 
On the other hand, considering that buckling of nanocolumns respond to a size effect, which is similar to that commonly assumed for hardness [Nix and Gao (1998)], we propose that the effect of buckling can be described by the following relation:

$$
E_{F}^{*}(h)=E_{2}\left(1+\frac{l_{2}}{h}\right)^{m}
$$

Where $E_{2}$ is the indentation elastic modulus of the layer for a penetration depth well above a second characteristic length $I_{2}$.

Then, through the combination of equations (2) and (3), it is possible to describe the evolution with depth of the apparent modulus by means of the relationship:

$$
E_{F}^{*}(h)=E_{L I N}\left(h-l_{1}\right) H\left(h-l_{1}\right)+E_{2}\left(1+\frac{l_{2}}{h}\right)^{m}
$$

In this expression a Heaviside $H$ function is added to the terms concerning the stiffening. In fact, stiffening does not appear at the first stages of deformation because the required buckling and contact between adjacent nanocolumns should have been induced previously.

Equation 4 can be simplified in the following cases: if stiffening does not play any role, then $E_{\text {LIN }}$ is set to 0 . In the same way, if no size effect due to buckling is expected, then $I_{2}=0$ and $m=1$.

To prove the reliability of this parametric formula, it has been used to adjust by a least squares method the evolution of the modulus obtained by FEM simulation. The following parameters have been obtained as a result of this fitting analysis: $E_{L I N}=1.8 \mathrm{TPa} / \mu \mathrm{m}, l_{1}=9 \mathrm{~nm}, E_{2}=1.2 \mathrm{GPa}, I_{2}=448 \mathrm{~nm}$ and $m=0.6$. It is noteworthy that the two obtained lengths $I_{1}$ and $I_{2}$ can be directly related to the thickness of the columns used for simulation and the thickness of the simulated structure, with values around 10 and $500 \mathrm{~nm}$, respectively. This similarity with the dimensions in the simulated structure supports the application of the outlined procedure to characterise and extract the mechanical properties of the OAD nanocolumnar thin films from experimental indentation data. It is remarkable that the obtained $m$ value obtained from the experimental data approaches 0.5 , i.e., the typical value encountered for classical length scale dependences such as those predicted by the Hall and Petch law [[41], [42]] and the Nix and Gao indentation size effect [[43]].

Following this approach and the assumption that $m=0.5$, a new minimisation gives $E_{L I N}=1.8 \mathrm{TPa} / \mu \mathrm{m}$, $I_{1}=10 \mathrm{~nm}, E_{2}=1.3 \mathrm{GPa}, I_{2}=974 \mathrm{~nm}$. Furthermore, taking into account that the column buckling initiates the contact between adjacent nanocolumns and this induces the film densification process, a description of mechanical properties relying on a single length scale should be, in principle, able to adjust the numerical results. Indeed, equation (4) can be further simplified assuming that $I_{1}=I_{2}$. This minimisation gives $E_{L I N}=1.7 \mathrm{TPa} / \mu \mathrm{m}, l_{1}=9 \mathrm{~nm}, E_{2}=7 \mathrm{GPa}$ and $m=0.9$. If, in addition, we assume $m=0.5$, the minimisation gives $E_{L I N}=1.8 \mathrm{TPa} / \mu \mathrm{m}, l_{1}=11 \mathrm{~nm}, E_{2}=10 \mathrm{GPa}$. It is noteworthy by these calculations that all determined $I_{1}$ values stay very close to the simulated columns size.

For the four minimisation schemes outlined above, the values obtained for the cost function are, respectively, 7.1e-3, 7.5e-3, 7.2e-3 and 9.2e-3. Thus, even if the analysis based on two length scales may be over-parameterized, the similarity of the cost function values support that, whatever the considered parametrization, the encountered length scales are in good agreement with the simulated values of nanocolumn size and/or multilayer thickness. We must note though that the elastic modulus of the nanocolumns material (i.e. $\mathrm{SiO}_{2}$ ) is not directly considered within this scheme and therefore it is not identified during the minimisation process. It must be also kept in mind that, if one wants to probe numerically the mechanical properties of the nanocolumns, calculations should be focused on the first stages of deformation. In practical terms the mesh describing the whole 
structure should be greatly refined making too long, in terms of calculation time, the analysis of the effect of nanostructure. It also appears that an experimental indentation test is unable to only probe the elasticity of the material composing the structure because the lateral size of the nanocolumns (i.e., between 83 and $128 \mathrm{~nm}$, see AFM analysis in Figure 3 ) is in the order of magnitude of the tip curvature of the indenter (evaluated in $113 \mathrm{~nm}$ ).

\section{Comparison between calculated and experimental results:}

Hardness and apparent indentation elastic modulus deduced for the different studied samples as a function of indentation depth have been presented in Figures 5 and 6 . For the determination of these apparent parameters, the indentation elastic modulus of the soda-lime glass substrate was measured under the assumption of a Poisson's ratio of 0.17 . The encountered value was $76 \mathrm{GPa}$, which is an accepted value for soda-lime glass [[35]].

To determine the film elastic modulus we carried out an inverse analysis based on the evolution of the apparent indentation modulus versus stiffness response. We assumed a substrate modulus of 76GPa and a Poisson ratio of 0.17 . Under these premises, it is possible to calculate a cost function based on the gap between the experimental and calculated values of $E_{a p p}^{*}$ according to eq. (1). Through the minimisation of this gap, it is possible to implement an identification procedure to reproduce the experimental response of each sample. For this aim, seven different approximations have been considered:

1. Approximation 1 assuming a constant elastic modulus according to the Bec et al (2010) approach (equation 1 )

2. Approximation $\mathbf{2}$ assuming exclusively the buckling of nanocolumns (equation 1 and 2)

3. Approximation $\mathbf{3}$ assuming exclusively the stiffening of columns (equation 1 and 3 )

4. Approximation 4 with two length scales (equation 1 and 4)

5. Approximation $\mathbf{5}$ with two length scales assuming a Hall-Petch (HP) behaviour (equation 1 and 4 with $m=0.5$ )

6. Approximation 6 with one length scale (equation 1 and 4 with $l_{2}=l_{1}$ )

7. Approximation 7 with one length scale assuming a HP behaviour (equation 1 and 4 with $I_{2}=I_{1}$ and $m=0.5$ ) 


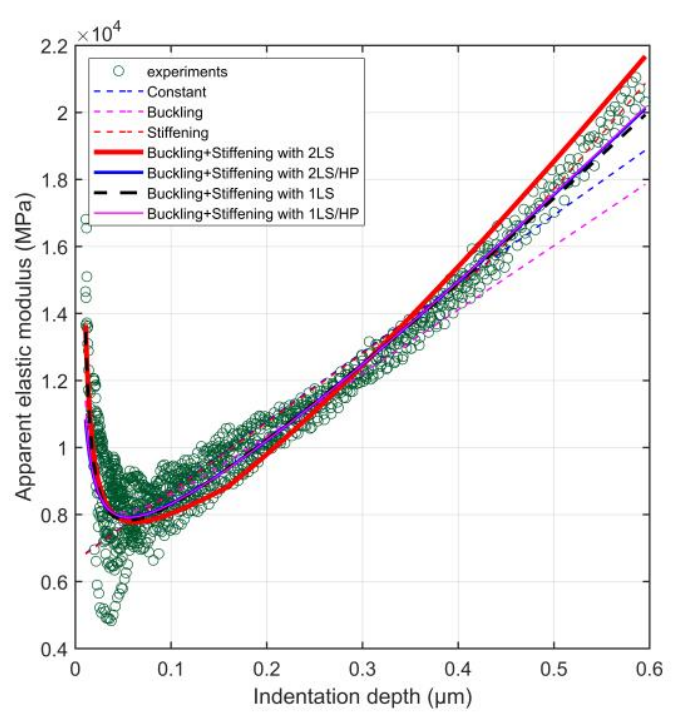

(c)

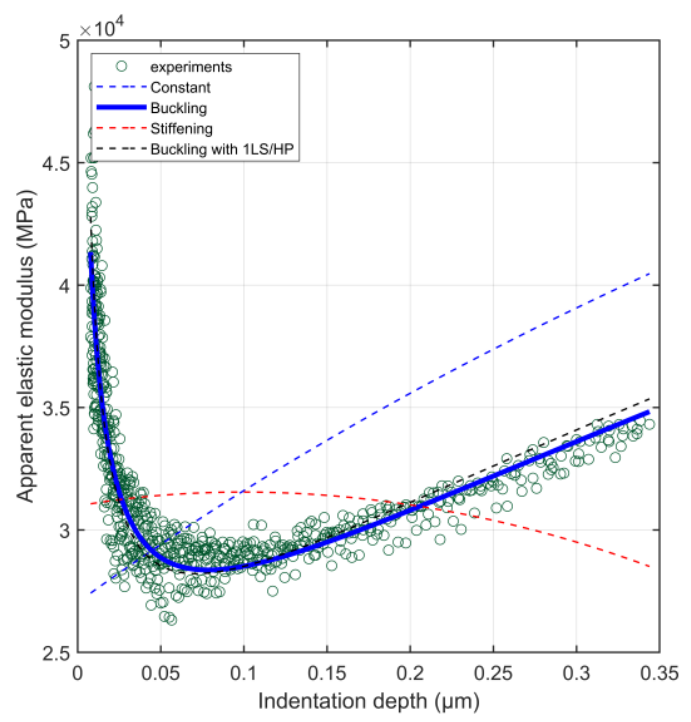

(e)

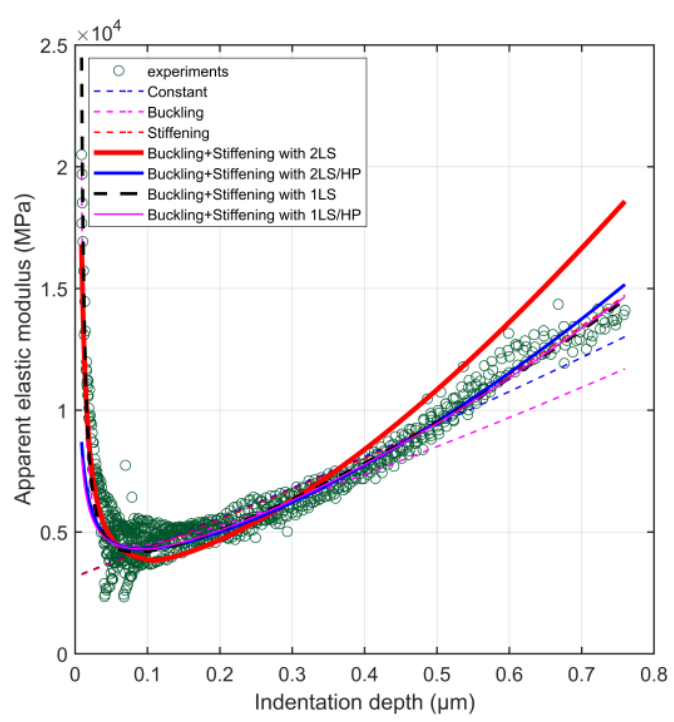

(d)

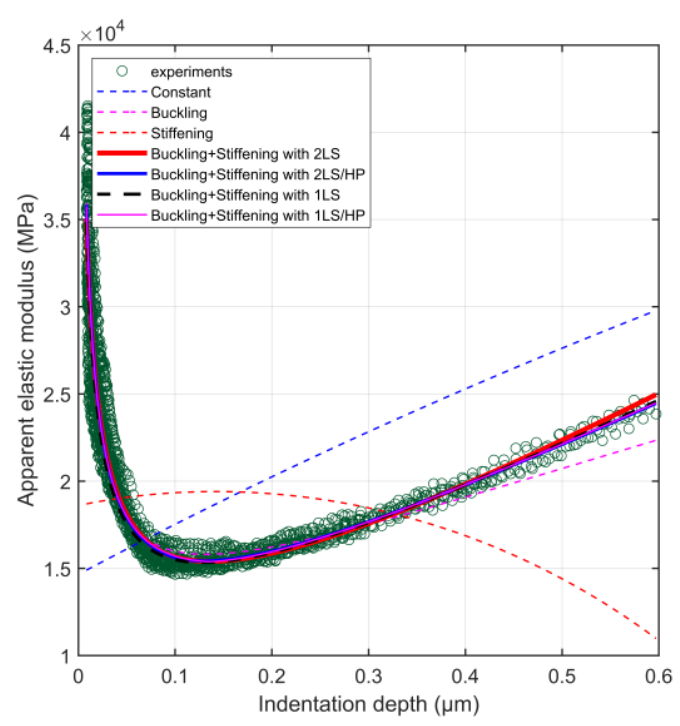

(f) 


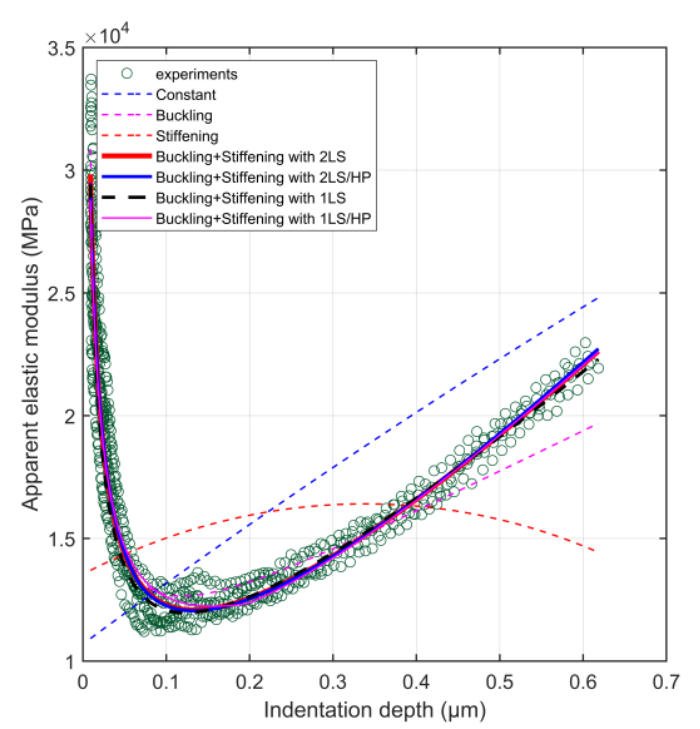

(g)

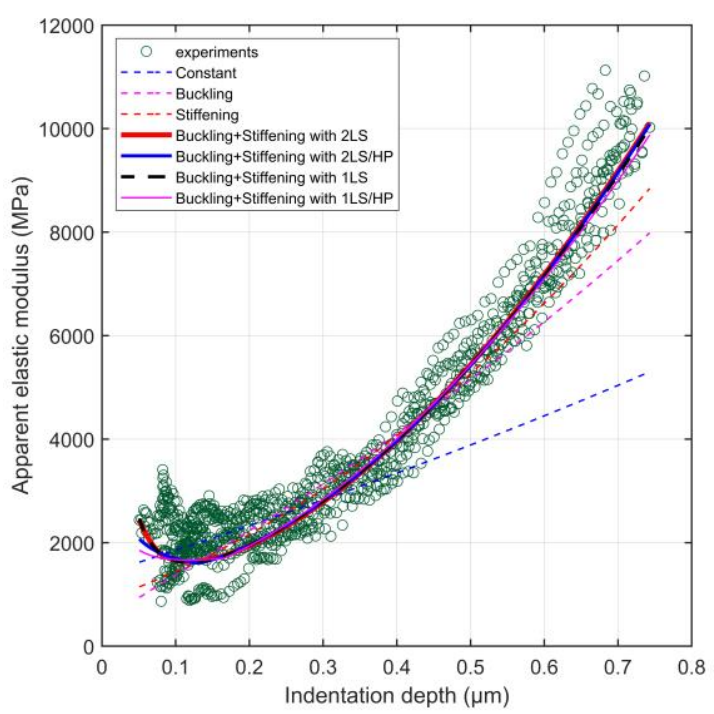

(i)

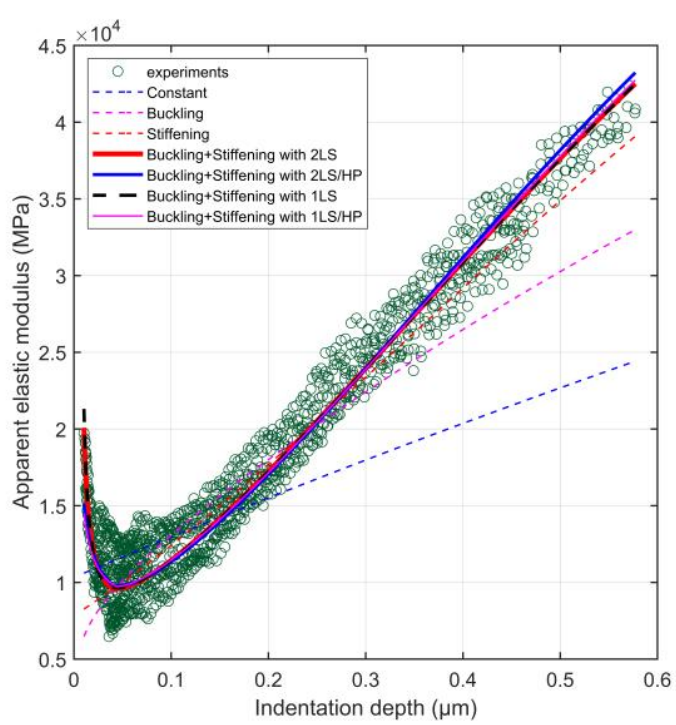

(h)

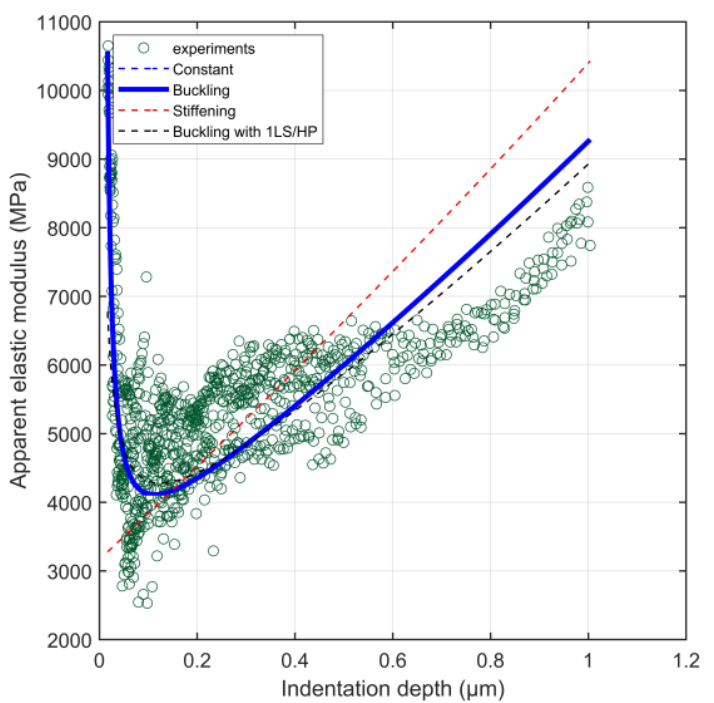

(j) 

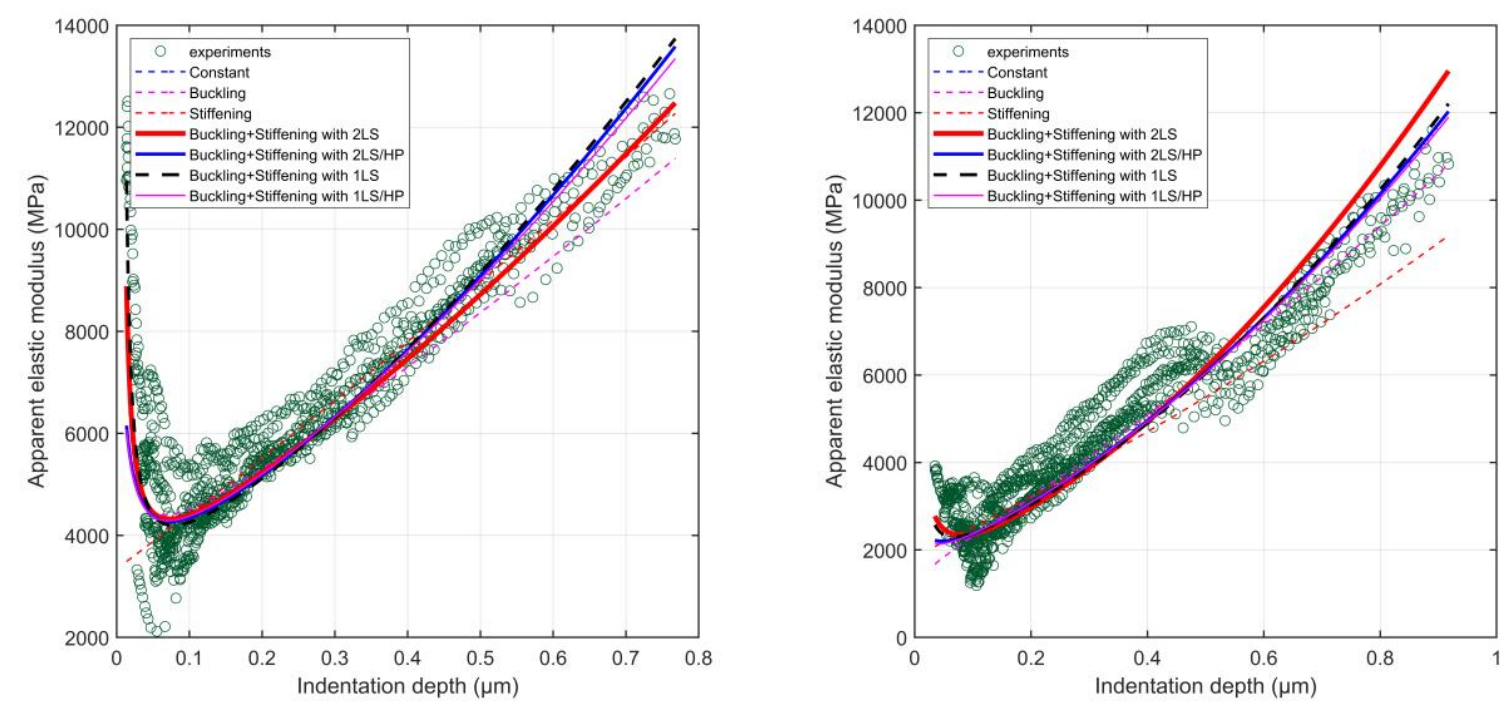

Figure 8: Comparison, as a function of indentation depth, between the evolution of the apparent elastic modulus $E_{a p p}^{*}$ derived from the experimental indentation results of investigated coatings and the seven approximations considered for evaluation. Results for samples (a) chiral CHL70, (b) chiral CHL80, (c) compact, (d) CSC70, (e) CSC80, (f) slanted S70, (g) S80, (h) vertical, (i) zigzag ZZ70, (j) zigzag ZZ80. Stiffening do not play any role for compact and vertical coatings so approximations (4) and (5) with two length scales are not presented for these two microstructures.

The result of this identification procedure is illustrated and summarised for all the different structures in figure 8 . From the plots in figure 8 it appears that experimental (green circles) and calculated (blue dotted lines) points do not overlap for the majority of samples when considering a constant elastic modulus (i.e., Bec et al. thin film approximation 1). An exception corresponds to the ZZ80 structures (figure 8j) where no loss of integrity was observed during the first stages of deformation, which points to a certain spring-like behaviour for the zigzag structure.

Approximation 2 (buckling only) appears to explain the behaviour of the vertical and compact samples, but for different reasons (figure $8 \mathrm{c}$ and $\mathrm{h}$ ). Either the samples do not suffer stiffening during the indentation process, as it happens for the compact layer, or the stiffening occurs at larger indentation depths, probably the case of vertical layers.

Approximation 3 (stiffening only) does not fit to any experimental sample behaviour, with the exception of sample zigzag ZZZO, very likely for the same reasons mentioned above. The observed discrepancies suggest that buckling is the most important phenomenon to take into account in order to reproduce correctly the behaviour of the samples under indentation.

Approximations 4 to $\mathbf{7}$ (buckling and stiffening) appear to reproduce very well the evolution of the apparent elastic modulus with the indentation depth of all samples. No significant difference is observed for these last four approximations and the experimental data. Differences appear for the values of the encountered parameters and particularly those of the characteristic length scales. Table 1, 2, 3 and 4, given in appendix A, summarise all the parameters encountered during the identification processes made with approximations 4 to 7 . Tables 1 and 2 give the parameters that provide the best adjustments obtained for each kind of thin film considering two length scales (with and without a HP behaviour). Meanwhile, in tables 3 and 4 we gather the parameters that provide the best adjustments obtained for each kind of thin film considering a single length scale (with and 
without HP behaviour). The adjustment performed considering a HP behaviour provides length scale values that appear to be related to the real dimensions of the microstructure (Table 1). In fact, regarding samples $Z Z 70$ and the $S 70$, lengths of $0.027 \mathrm{~nm}$ and $0.071 \mathrm{~nm}$ do not seem to be relevant, except if stiffening starts at the first stages of deformation. The length scales obtained considering a HP behaviour and a single length scale are comprised between 21 and $200 \mathrm{~nm}$ and between 20 to $5900 \mathrm{~nm}$ considering two length scales. Figure 9 presents the length scales $I 1$ and 12 found for approximations 5 and 7 (HP). Average values of $42 \pm 18 \mathrm{~nm}$ and $121 \pm 71 \mathrm{~nm}$ are obtained. Even if these values are not exactly those of the lateral nanocolumn width $(83-128 \mathrm{~nm})$, the stacking period (200$400 \mathrm{~nm})$ or the film thickness (1300-2000 nm), they are at least within the actual order of magnitude of the actual dimensions. This similarity shows that approximations relying on the HP assumption fit well with the indentation data and can be used to reliably characterise the microstructure of the layers. However, as the numerical simulation does not take into account the particular inclination and shape of nanocolumns, it should be further improved to accurately reproduce the nanostructural characteristics of each type of layer structure.

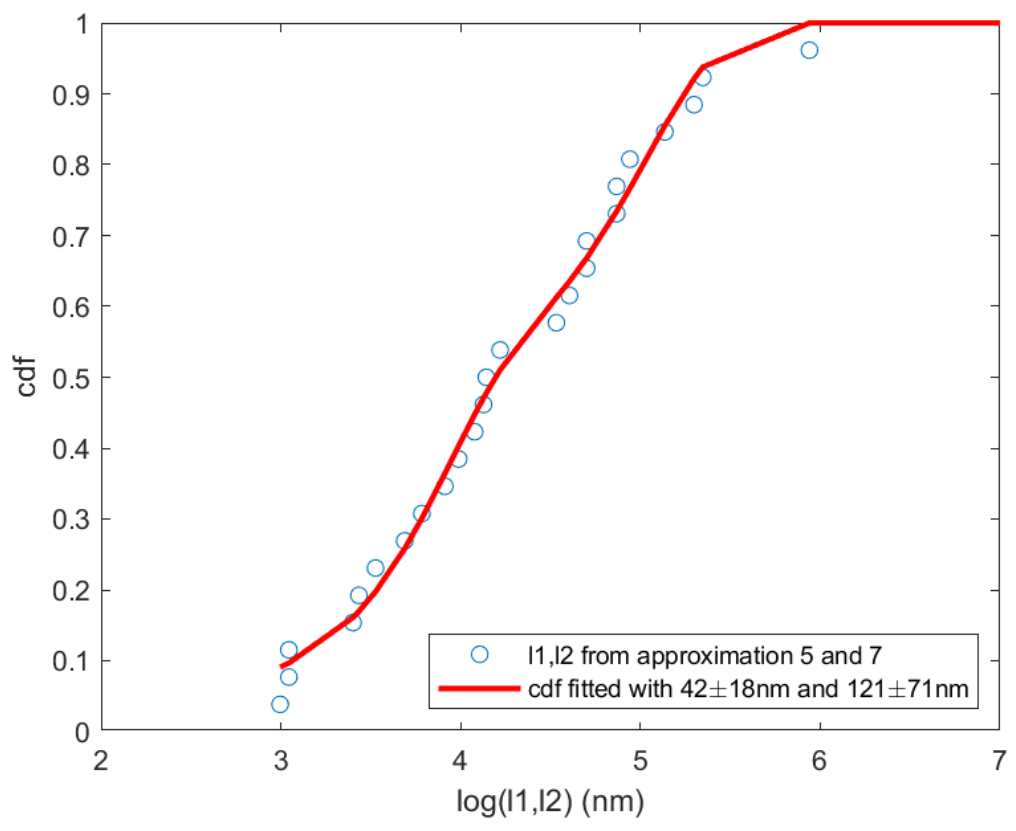

Figure 9: cumulative density function of $\mathrm{I}_{1}$ and $\mathrm{I}_{2}$ extracted from approximations 5 and 7.

Within this evaluation scheme, CSC samples deserve a particular attention because the model appears to reproduce particularly well the experimental results. For these samples the decrease in equivalent modulus with indentation depth is the slowest of the whole series of analysed samples and renders relatively higher values of $I_{2}$ as compared with those of the other samples (i.e., 140 and $380 \mathrm{~nm}$ ). It is also noteworthy that $I_{2}$ value is nearly $400 \mathrm{~nm}$ for the $\operatorname{CSC} 80$, i.e., close to the value of the stacking period in the two examined CSC structures. Furthermore, extrapolating the value of the equivalent film modulus to a zero indentation depth, one would obtained the value encountered for a compact film, as expected for the termination in these layer structures. However, since stiffening occurs in the CSC samples but not in the compact one, we attribute this difference to the densification of the slanted segments of the CSC structure. Furthermore, the values obtained for $I_{1}$ 
(100 and 68nm) reproduce reasonably well the value experimentally found by AFM in figure 3 $(100 \pm 31 \mathrm{~nm})$.

\section{Conclusions:}

The behaviour of multi-layered PVOAD columnar structures under instrumented indentation have been studied experimentally and numerically. The following conclusions can be drawn from this analysis:

(i) Although all multilayers present a similar chemical composition and similar thickness, they have very different mechanical responses, indicating a strong affectation of mechanical properties by their microstructure in terms of stacking period, compactness and nanocolumns size.

(ii) The numerical model developed here is able to reproduce various experimental phenomena, such as hysteresis, pop-in, shear bands or dissipation effects, this latter characterised by a phase shift between force and displacement.

(iii) The indentation behaviour is controlled by two mechanisms: buckling of the column and densification of the layer under the action of indenter. Particularly, buckling of the columns seems to be responsible for the displacement burst that, observed on the load-displacement curves, induces friction between the columns as revealed by non-zero phase shifts measured experimentally. Densification of the layer causes a stiffening of the multilayer under indentation.

(iv) Buckling and stiffening are related to the two length scales that can be extracted from the particular elastic response of the films as a function of the indenter displacement. The encountered length scales are in a good agreement with the microstructure of the film (columns width) and the layer thickness. Indeed, the herein proposed model, based on two length scales accounting for two distinct phenomena namely buckling and densification, can reliably characterise the microstructure of such type of coatings.

Finally, the identification of the actual microstructure of a given sculptured multilayer would require a more sophisticated numerical model enabling a more detailed description of the structure in each case. In particular, the inclination of the columns and the alternation between different segments seem essential characteristics to account for the different experimental behaviours. The simulation of these structural features constitutes the basis of a research plan to predict the actual microstructure of sculptured nanocolumnar films from the analysis of their indentation behaviour.

\section{Acknowledgments:}

Work funded in part through the Spanish Ministry of Science, Education and Universities through grant: PGC2018-096855-B-C41. Authors also thank the FEDER program through AEI-MICINN (PID2019-110430GB-C21) and Junta de Andalucía (PAIDI-2020 through project P18-RT-3480) for financial support.

\section{References:}


[1] R. Lakhtakia, A. and Messier, Sculptured Thin Films: Nanoengineered Morphology and Optics. SPIE Press, 2005.

[2] S. Liedtke, C. Grüner, J. W. Gerlach, and B. Rauschenbach, "Comparative study of sculptured metallic thin films deposited by oblique angle deposition at different temperatures," Beilstein J. Nanotechnol., vol. 9, no. 1, pp. 954-962, 2018, doi: 10.3762/bjnano.9.89.

[3] K. Kim, J. H. Park, H. Kim, J. K. Kim, E. Fred Schubert, and J. Cho, "Energy bandgap variation in oblique angle-deposited indium tin oxide," Appl. Phys. Lett., vol. 108, no. 4, pp. 1-4, 2016, doi: 10.1063/1.4940998.

[4] L. González-García et al., "Correlation lengths, porosity and water adsorption in TiO 2 thin films prepared by glancing angle deposition," Nanotechnology, vol. 23, no. 20, 2012, doi: 10.1088/0957-4484/23/20/205701.

[5] C. M. Zhou and D. Gall, "Branched Ta nanocolumns grown by glancing angle deposition," Appl. Phys. Lett., vol. 88, no. 20, pp. 23-25, 2006, doi: 10.1063/1.2204759.

[6] S. V. Kesapragada and D. Gall, "Anisotropic broadening of Cu nanorods during glancing angle deposition," Appl. Phys. Lett., vol. 89, no. 20, pp. 1-3, 2006, doi: 10.1063/1.2388861.

[7] F. Ruffino and M. G. Grimaldi, "Control of the kinetic roughening in nanostructured ag films by oblique sputter-depositions," Nanosci. Nanotechnol. Lett., vol. 4, no. 3, pp. 309-315, 2012, doi: 10.1166/nnl.2012.1310.

[8] A. Garcia-Valenzuela, R. Alvarez, V. Rico, J. Cotrino, A. R. Gonzalez-Elipe, and A. Palmero, "Growth of nanocolumnar porous $\mathrm{TiO} 2$ thin films by magnetron sputtering using particle collimators," Surf. Coatings Technol., vol. 343, pp. 172-177, 2018, doi: 10.1016/j.surfcoat.2017.09.039.

[9] M. J. B. M.M. Hawkeye, M.T. Taschuk, Glancing Angle Deposition of Thin Films: Engineering the Nanoscale. 2014.

[10] A. Barranco, A. Borras, A. R. Gonzalez-Elipe, and A. Palmero, "Perspectives on oblique angle deposition of thin films: From fundamentals to devices," Prog. Mater. Sci., vol. 76, pp. 59-153, 2016, doi: 10.1016/j.pmatsci.2015.06.003.

[11] K. M. Krause and M. J. Brett, "Spatially graded nanostructured chiral films as tunable circular polarizers," Adv. Funct. Mater., vol. 18, no. 20, pp. 3111-3118, 2008, doi: 10.1002/adfm.200800685.

[12] van K. H. and and L. C., "Tailoring growth and local composition by oblique-incidence deposition: a review and new experimental data," Mater. Sci. Eng., pp. 295-354, 1994.

[13] M. Oliva-Ramirez, A. Barranco, M. Löffler, F. Yubero, and A. R. González-Elipe, "Optofluidic modulation of self-associated nanostructural units forming planar bragg microcavities," ACS Nano, vol. 10, no. 1, pp. 1256-1264, 2016, doi: 10.1021/acsnano.5b06625.

[14] I. Hodgkinson, Q. hong Wu, B. Knight, A. Lakhtakia, and K. Robbie, "Vacuum deposition of chiral sculptured thin films with high optical activity," Appl. Opt., vol. 39, no. 4, p. 642, 2000, doi: 10.1364/ao.39.000642.

[15] K. Yonezawa, Y. Kozawa, and S. Sato, "Generation of a radially polarized laser beam by use of the birefringence of a c-cut Nd:YVO4 crystal," Opt. Lett., vol. 31, no. 14, p. 2151, 2006, doi: 10.1364/ol.31.002151.

[16] F. Zhang, J. Xu, A. Lakhtakia, T. Zhu, S. M. Pursel, and M. W. Horn, "Circular polarization emission from an external cavity diode laser," Appl. Phys. Lett., vol. 92, no. 11, pp. 1-4, 2008, 
doi: $10.1063 / 1.2896306$.

[17] M. Oliva-Ramírez et al., "Liquid switchable radial polarization converters made of sculptured thin films," Appl. Surf. Sci., vol. 475, pp. 230-236, 2019, doi: 10.1016/j.apsusc.2018.12.200.

[18] M. Stalder and M. Schadt, "Linearly polarized light with axial symmetry generated by liquidcrystal polarization converters," Opt. Lett., vol. 21, no. 23, p. 1948, 1996, doi: 10.1364/ol.21.001948.

[19] X. Chen, R. Wang, N. Yao, A. G. Evans, J. W. Hutchinson, and R. W. Bruce, "Foreign object damage in a thermal barrier system: Mechanisms and simulations," Mater. Sci. Eng. A, vol. 352, no. 1-2, pp. 221-231, 2003, doi: 10.1016/S0921-5093(02)00905-X.

[20] X. Chen, M. Y. He, I. Spitsberg, N. A. Fleck, J. W. Hutchinson, and A. G. Evans, "Mechanisms governing the high temperature erosion of thermal barrier coatings," Wear, vol. 256, no. 7-8, pp. 735-746, 2004, doi: 10.1016/S0043-1648(03)00446-0.

[21] M. Watanabe, T. Xu, C. G. Levi, A. S. Gandhi, and A. G. Evans, "Shear band formation in columnar thermal barrier oxides," Acta Mater., vol. 53, no. 13, pp. 3765-3773, 2005, doi: 10.1016/j.actamat.2005.04.029.

[22] Y. Gaillard, E. Jimenez-Pique, and M. Anglada, "Scale dependence of the Young's modulus measured by nanoindentation in columnar YSZ EB-PVD thermal barriers coatings," Philos. Mag., vol. 86, no. 33-35, pp. 5441-5451, Nov. 2006, doi: 10.1080/14786430600778674.

[23] M. R. Maschmann, Q. Zhang, F. Du, L. Dai, and J. Baur, "Length dependent foam-like mechanical response of axially indented vertically oriented carbon nanotube arrays," Carbon N. Y., vol. 49, no. 2, pp. 386-397, 2011, doi: 10.1016/j.carbon.2010.09.034.

[24] J. Lintymer, N. Martin, J. M. Chappé, P. Delobelle, and J. Takadoum, "Influence of zigzag microstructure on mechanical and electrical properties of chromium multilayered thin films," Surf. Coatings Technol., vol. 180-181, pp. 26-32, 2004, doi: 10.1016/j.surfcoat.2003.10.027.

[25] Y. Gaillard, V. J. Rico, E. Jimenez-Pique, and A. R. González-Elipe, "Nanoindentation of TiO2 thin films with different microstructures," J. Phys. D. Appl. Phys., vol. 42, no. 14, 2009, doi: 10.1088/0022-3727/42/14/145305.

[26] E. Jiménez-Piqué, L. González-García, V. J. Rico, and A. R. González-Elipe, "Nanoindentation of nanocolumnar TiO2 thin films with single and stacked zig-zag layers," Thin Solid Films, vol. 550, pp. 444-449, 2014, doi: 10.1016/j.tsf.2013.10.022.

[27] M. W. Crowell, J. Wang, R. M. McMeeking, and A. G. Evans, "Dynamics of kink band formation in columnar thermal barrier oxides," Acta Mater., vol. 56, no. 16, pp. 4150-4159, 2008, doi: 10.1016/j.actamat.2008.04.058.

[28] T. Zisis and N. A. Fleck, "The elastic-plastic indentation response of a columnar thermal barrier coating," Wear, vol. 268, no. 3-4, pp. 443-454, 2010, doi: 10.1016/j.wear.2009.08.035.

[29] X. Chen, J. W. Hutchinson, and A. G. Evans, "Simulation of the high temperature impression of thermal barrier coatings with columnar microstructure," Acta Mater., vol. 52, no. 3, pp. 565571, 2004, doi: 10.1016/j.actamat.2003.09.047.

[30] L. Wang et al., "Finite element simulation of surface micro-indentation behavior of yttria stabilized zirconia thermal barrier coatings with microstructural characteristic of columnar grains and sub-grains based on a nonlinear contact model," Comput. Mater. Sci., vol. 82, pp. 244-256, 2014, doi: 10.1016/j.commatsci.2013.09.034.

[31] L. J.-L. Bec Sandrine, Tonck Andre, "A simple guide to determine elastic properties of films on 
substrate from nanoindentation experiments," Philos. Mag., no. september, pp. 1-36, 2010.

[32] C. Lopez-Santos et al., "Nanocolumnar association and domain formation in porous thin films grown by evaporation at oblique angles," Nanotechnology, vol. 27, no. 39, 2016, doi: 10.1088/0957-4484/27/39/395702.

[33] I. Horcas, R. Fernández, J. M. Gómez-Rodríguez, J. Colchero, J. Gómez-Herrero, and A. M. Baro, "WSXM: A software for scanning probe microscopy and a tool for nanotechnology," Rev. Sci. Instrum., vol. 78, no. 1, pp. 1-8, 2007, doi: 10.1063/1.2432410.

[34] W. C. Oliver and G. M. Pharr, "An improved technique for determining hardness and elastic modulus using load and displacement sensing indentation experiments," Journal of Materials Research, vol. 7, no. 06. pp. 1564-1583, 1992, [Online]. Available: http://www.journals.cambridge.org/abstract\%7B_\%7DS0884291400017039.

[35] G. Kermouche et al., "Mechanical modeling of indentation-induced densification in amorphous silica To cite this version : HAL Id : hal-00260324 Mechanical modelling of indentation-induced densification in amorphous silica," 2008.

[36] A. Argon, "Plastic deformation in metallic glasses," Acta Metall., vol. 27, pp. 47-58, 1979, [Online]. Available: http://www.ncbi.nlm.nih.gov/pubmed/4503234.

[37] J. Perez, Matériaux non cristallins et science du désordre. 2001.

[38] H. G. Bulychev SI, Alekhin VP, Shorshorov MH, Ternovskii AP, "Determining Young's modulus from the indentor penetrating diagram," Ind Lab, vol. 41, pp. 1409-1412, 1975.

[39] I. N. Sneddon, "The relation between load and penetration in the axisymmetric boussinesq problem for a punch of arbitrary profile," Int. J. Eng. Sci., vol. 3, no. 1, pp. 47-57, 1965, doi: 10.1016/0020-7225(65)90019-4.

[40] D. Mercier, V. Mandrillon, M. Verdier, and Y. Brechet, "Young's modulus measurement of a thin film from experimental nanoindentation performed on multilayer systems," Mater. Tech., vol. 99, no. 2, pp. 169-178, 2011, doi: 10.1051/mattech/2011029.

[41] E. O. Hall, "The deformation and ageing of mild steel: II Characteristics of the Lüders deformation," Proc. Phys. Soc. Sect. B, vol. 64, no. 9, pp. 742-747, 1951, doi: 10.1088/0370$1301 / 64 / 9 / 302$.

[42] N. Petch, "The Cleavage Strength of Polycrystals," J. iron steel Inst., pp. 25-28, 1953.

[43] W. D. Nix and H. Gao, "Indentation size effects in crystalline materials: A law for strain gradient plasticity," J. Mech. Phys. Solids, vol. 46, no. 3, pp. 411-425, 1998, doi: 10.1016/S0022-5096(97)00086-0.

\section{Annexes A:}

\begin{tabular}{|l|l|l|l|l|l|l|}
\hline Samples & $\begin{array}{l}E_{\text {LIN }} \\
(\mathrm{MPa} / \mathrm{mm})\end{array}$ & $I_{1}(\mathrm{~mm})$ & $E_{2}(\mathrm{MPa})$ & $I_{2}(\mathrm{~mm})$ & $\mathrm{m}$ & $\begin{array}{l}\text { Cost } \\
\text { function }\end{array}$ \\
\hline ZZ70 & $7.4 \mathrm{e} 5$ & $2.7 \mathrm{e}-8$ & $2.8 \mathrm{e} 3$ & $7.8 \mathrm{e}-7$ & 20.0 & $2.4 \mathrm{e}-2$ \\
\hline ZZ80 & $1.6 \mathrm{e} 6$ & $1 \mathrm{e}-4$ & $1.4 \mathrm{e} 3$ & $1 \mathrm{e}-5$ & 2.4 & $3.6 \mathrm{e}-2$ \\
\hline CHL70 & $5.2 \mathrm{e} 6$ & $1.6 \mathrm{e}-4$ & $5.5 \mathrm{e} 3$ & $3.9 \mathrm{e}-6$ & 2.8 & $1.2 \mathrm{e}-2$ \\
\hline
\end{tabular}




\begin{tabular}{|l|l|l|l|l|l|l|}
\hline CHL80 & $4.7 \mathrm{e} 6$ & $1.1 \mathrm{e}-4$ & $1.7 \mathrm{e} 3$ & $6.1 \mathrm{e}-5$ & 1.1 & $2.2 \mathrm{e}-2$ \\
\hline Compact & 0 (fixed) & $/$ & $2.1 \mathrm{e} 4$ & $4.4 \mathrm{e}-5$ & 0.3 & $1.8 \mathrm{e}-3$ \\
\hline CSC70 & $6.3 \mathrm{e} 6$ & $7.9 \mathrm{e}-5$ & $7.1 \mathrm{e} 3$ & $2.9 \mathrm{e}-4$ & 0.45 & $5.2 \mathrm{e}-3$ \\
\hline CSC80 & $6.9 \mathrm{e} 6$ & $1.1 \mathrm{e}-5$ & $4.2 \mathrm{e} 3$ & $3.6 \mathrm{e}-4$ & 0.53 & $5.6 \mathrm{e}-3$ \\
\hline S70 & $2.9 \mathrm{e} 7$ & $3.9 \mathrm{e}-5$ & $6.5 \mathrm{e} 3$ & $7.1 \mathrm{e}-8$ & 161.7 & $1.6 \mathrm{e}-2$ \\
\hline S80 & $3.6 \mathrm{e} 6$ & $8.0 \mathrm{e}-5$ & $3.0 \mathrm{e} 2$ & $2.4 \mathrm{e}-4$ & 1.1 & $4.3 \mathrm{e}-2$ \\
\hline Vertical & 0 (fixed) & $/$ & $2.7 \mathrm{e} 3$ & $7.6 \mathrm{e}-11$ & $2.9 \mathrm{e} 5$ & $2.7 \mathrm{e}-2$ \\
\hline
\end{tabular}

Table 1: identified values of $E_{L I N}, I_{1}, E_{2}, I_{2}$ and $m$ for the different samples with models using two internal lengths.

\begin{tabular}{|c|c|c|c|c|c|c|}
\hline Samples & $\begin{array}{l}E_{\text {LIN }} \\
(\mathrm{MPa} / \mathrm{mm})\end{array}$ & $I_{1}(\mathrm{~mm})$ & $\mathrm{E}_{2}(\mathrm{MPa})$ & $\mathrm{I}_{2}(\mathrm{~mm})$ & $\mathrm{m}$ & $\begin{array}{l}\text { Cost } \\
\text { function }\end{array}$ \\
\hline ZZ70 & $1.6 \mathrm{e} 6$ & $6.3 e-5$ & $2.6 \mathrm{e} 3$ & $5.9 e-5$ & \multirow[t]{10}{*}{0.5} & $2.7 e-2$ \\
\hline ZZ80 & $1.1 \mathrm{e} 6$ & $1.1 \mathrm{e}-4$ & $1.6 \mathrm{e} 3$ & $2.0 e-5$ & & $3.6 e-2$ \\
\hline CHL70 & $2.9 \mathrm{e} 6$ & $3.4 \mathrm{e}-5$ & $5.4 \mathrm{e} 3$ & $3.0 e-5$ & & $1.1 \mathrm{e}-2$ \\
\hline CHL80 & $2.6 \mathrm{e} 6$ & $5 e-5$ & $1.7 \mathrm{e} 3$ & $2.1 \mathrm{e}-4$ & & $2.6 \mathrm{e}-2$ \\
\hline Compact & 0 (fixed) & 1 & $2.2 \mathrm{e} 4$ & $2.1 \mathrm{e}-5$ & & $1.9 \mathrm{e}-3$ \\
\hline CSC70 & $4.2 \mathrm{e} 6$ & $1.0 \mathrm{e}-4$ & $8.4 \mathrm{e} 3$ & $1.4 \mathrm{e}-4$ & & $5.2 e-3$ \\
\hline CSC80 & $7.2 \mathrm{e} 6$ & $6.8 e-5$ & $4.4 \mathrm{e} 3$ & $3.8 \mathrm{e}-4$ & & $5.5 e-3$ \\
\hline S70 & $3.2 \mathrm{e} 7$ & $4 e-5$ & $5.6 \mathrm{e} 3$ & $6.2 e-5$ & & $1.6 \mathrm{e}-2$ \\
\hline S80 & $3.8 \mathrm{e} 6$ & $1.3 \mathrm{e}-4$ & $1.6 \mathrm{e} 2$ & $5.9 e-3$ & & $4.3 e-2$ \\
\hline Vertical & 0 (fixed) & / & $2.6 \mathrm{e} 3$ & $9.3 e-5$ & & $2.9 e-2$ \\
\hline
\end{tabular}

Table 2: identified values of $E_{L I N}, I_{1}, E_{2}$ and $I_{2}$ or the different samples with models using two internal lengths and assuming a constant value of $m=0.5$

\begin{tabular}{|l|l|l|l|l|l|}
\hline Samples & $\begin{array}{l}E_{\text {LIN }} \\
(\mathrm{MPa} / \mathrm{mm})\end{array}$ & $I(\mathrm{~mm})$ & $\mathrm{E}_{2}(\mathrm{MPa})$ & $\mathrm{m}$ & Cost function \\
\hline ZZ70 & $6.6 \mathrm{e} 4$ & $3.0 \mathrm{e}-10$ & $2.6 \mathrm{e} 3$ & $1.6 \mathrm{e} 6$ & $2.3 \mathrm{e}-2$ \\
\hline ZZ80 & $2.6 \mathrm{e} 6$ & $5.9 \mathrm{e}-10$ & $1.3 \mathrm{e} 3$ & $2.9 \mathrm{e} 4$ & $3.7 \mathrm{e}-2$ \\
\hline CHL70 & $2.5 \mathrm{e} 6$ & $3.0 \mathrm{e}-5$ & $5.4 \mathrm{e} 3$ & 11.6 & $1.1 \mathrm{e}-2$ \\
\hline CHL80 & $1.7 \mathrm{e} 6$ & $5 \mathrm{e}-6$ & $2.2 \mathrm{e} 3$ & 5.3 & $2.0 \mathrm{e}-2$ \\
\hline CSC70 & $4.6 \mathrm{e} 6$ & $1.47 \mathrm{e}-4$ & $8.4 \mathrm{e} 3$ & 0.49 & $5.2 \mathrm{e}-3$ \\
\hline CSC80 & $5.2 \mathrm{e} 6$ & $1.35 \mathrm{e}-4$ & $6.1 \mathrm{e} 3$ & 0.57 & $5.7 \mathrm{e}-3$ \\
\hline S70 & $3.1 \mathrm{e} 7$ & $1.5 \mathrm{e}-10$ & $5.6 \mathrm{e} 3$ & $9 \mathrm{e} 4$ & $1.7 \mathrm{e}-2$ \\
\hline S80 & $3.4 \mathrm{e} 6$ & $7.9 \mathrm{e}-5$ & $4.1 \mathrm{e} 2$ & 1.8 & $4.3 \mathrm{e}-2$ \\
\hline
\end{tabular}

Table 3: identified values of $E_{L I N}, I_{1}, E_{2}$ and $m$ for the different samples with models using a single internal length.

\begin{tabular}{|c|c|c|c|c|c|}
\hline Samples & $\begin{array}{l}E_{\text {LIN }} \\
(\mathrm{MPa} / \mathrm{mm})\end{array}$ & $I(\mathrm{~mm})$ & $\mathrm{E}_{2}(\mathrm{MPa})$ & $\mathrm{m}$ & Cost function \\
\hline ZZ70 & $1.4 \mathrm{e} 6$ & $5.4 e-5$ & $2.6 \mathrm{e} 3$ & \multirow[t]{8}{*}{0.5} & $2.7 e-2$ \\
\hline ZZ80 & $1.1 \mathrm{e} 6$ & $2.1 \mathrm{e}-5$ & $1.5 \mathrm{e} 3$ & & $3.7 e-2$ \\
\hline CHL70 & $3.0 \mathrm{e} 6$ & $3.1 \mathrm{e}-5$ & $5.3 \mathrm{e} 3$ & & $1.1 \mathrm{e}-2$ \\
\hline CHL80 & $2.0 \mathrm{e} 6$ & $1.1 \mathrm{e}-4$ & $2.1 \mathrm{e} 3$ & & $2.6 e-2$ \\
\hline CSC70 & $2.6 \mathrm{e} 6$ & $1.3 e-4$ & $8.5 \mathrm{e} 3$ & & $5.2 e-3$ \\
\hline CSC80 & $6.4 \mathrm{e} 6$ & $2 e-4$ & $5.9 \mathrm{e} 3$ & & $6.1 \mathrm{e}-3$ \\
\hline S70 & $3.0 \mathrm{e} 7$ & $4.4 e-5$ & $6.2 \mathrm{e} 3$ & & $1.7 e-2$ \\
\hline $\mathrm{S} 80$ & $3.2 \mathrm{e} 6$ & $1.7 e-4$ & $7.7 \mathrm{e} 2$ & & $4.3 e-2$ \\
\hline
\end{tabular}


Table 4: identified values of $E_{L I N}, I_{1}$ and $E_{2}$ for the different samples with models using a single internal length. and assuming a constant value of $m=0.5$ 